CAMILA MERIDA CARRILLO

\title{
Necessidade de cuidados paliativos odontológicos em crianças com doenças crônicas. Caracterização de amostra
}

Dissertação apresentada à Faculdade de Medicina da Universidade de São Paulo para obtenção do título de Mestre em Ciências.

Programa de Neurologia

Orientador: Dr. José Tadeu Tesseroli de Siqueira

São Paulo 
Dados Internacionais de Catalogação na Publicação (CIP)

Preparada pela Biblioteca da

Faculdade de Medicina da Universidade de São Paulo

Creprodução autorizada pelo autor

Carrillo, Camila Merida

Necessidade de cuidados paliativos odontológicos em crianças com doenças crônicas. Caracterização de amostra / Camila Merida Carrillo. -- São Paulo, 2011.

Dissertação(mestrado)--Faculdade de Medicina da Universidade de São Paulo. Programa de Neurologia.

Orientador: José Tadeu Tesseroli de Siqueira.

Descritores: 1.Cuidados paliativos 2.Saúde bucal 3.Doença crônica 4.Qualidade de vida 5.Criança 6.Adolescente

USP/FM/DBD-121/11 
Esta dissertação está de acordo com as seguintes normas,:

Referências: adaptado de International Committee of Medical Journals Editors (Vancouver)

Universidade de São Paulo. Faculdade de Medicina. Serviço de Biblioteca e Documentação. Guia de apresentação de dissertações, teses e monografias. Elaborado por Anneliese Carneiro da Cunha, Maria Julia de A. L. Freddi, Maria F. Crestana, Marinalva de Souza Aragão, Suely Campos Cardoso, Valéria Vilhena. 2a ed.São Paulo: Serviço de Biblioteca e Documentação; 2005.

Abreviaturas dos títulos dos periódicos de acordo com List of Journals Indexed in Index Medicus. 


\section{SUMÁRIO}

LISTA DE ABREVIATURAS E SIGLAS

LISTA DE FIGURAS

LISTA DE TABELAS

RESUMO

SUMMARY

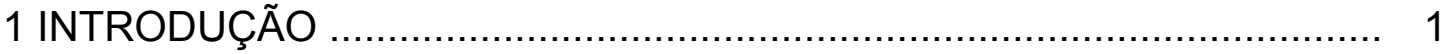

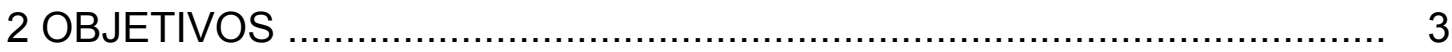

3 REVISÃO DE LITERATURA _........................................................ 4

3.1 CUIDADOS PALIATIVOS ……........................................................ 4

3.1.2 CUIDADOS PALIATIVOS EM PEDIATRIA …........................................... 4

3.1.3 DOENÇAS ONCOLÓGICAS .......................................................... 8

3.1.3.1 MANIFESTAÇÕES BUCAIS DAS DOENÇAS ONCOLÓGICAS ........................ 10

3.1.4 EPIDERMÓLISE BOLHOSA ............................................................. 14

3.1.4.1 MANIFESTAÇÕES BUCAIS DA EPIDERMÓLISE BOLHOSA ......................... 21

3.2 SAÚde BUCAL E ATENÇÃo OdONTOLÓGICA EM CRIANÇAS SOB CUIDADOS

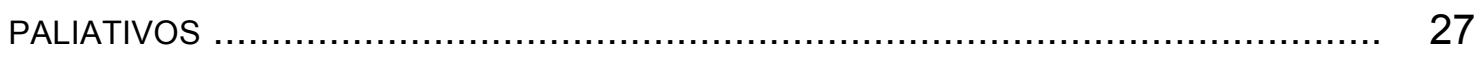

3.2.1 SAÚDE BUCAL E ATENÇÃO ODONTOLÓGICA …...................................... 27

3.2.2 EPIDEMIOLOGIA DA CÁRIE E DA DOENÇA PERIODONTAL ........................... 28

3.2.3 SAÚDE BUCAL EM CRIANÇAS COM DOENÇAS SISTÊMICAS ........................ 30 
3.2.4 O CIRURGIÃO-DENTISTA NA EQUIPE DE CUIDADOS PALIATIVOS.................. 32

4 CASUÍSTICA E MÉTODOS ............................................................. 34

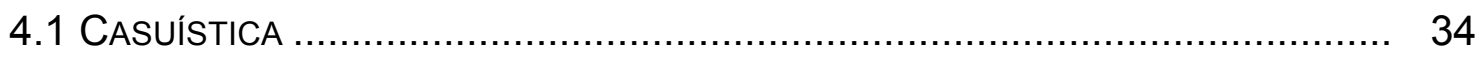

4.1.1 CRITÉRIOS DE INCLUSÃO ……................................................. 34

4.1.2 CRITÉRIOS DE EXCLUSÃO ........................................................... 35

4.1.3 GRUPOS DE ESTUDO …...................................................... 35

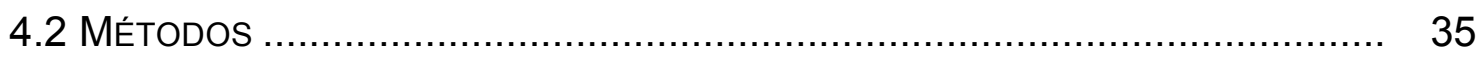

4.2.1 VARIÁVEIS SÓCIO-DEMOGRÁFICAS .................................................... 35

4.2.2 INSTRUMENTOS DE AVALIAÇÃO ........................................................... 36

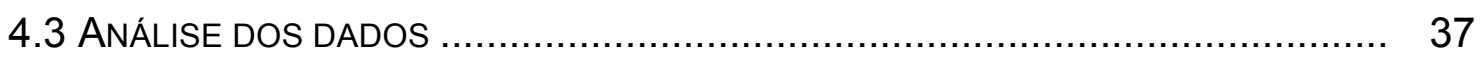

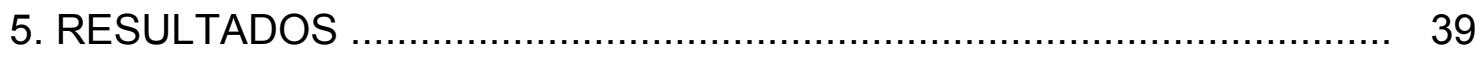

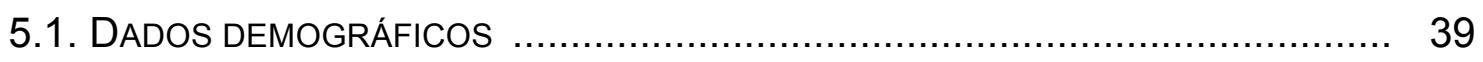

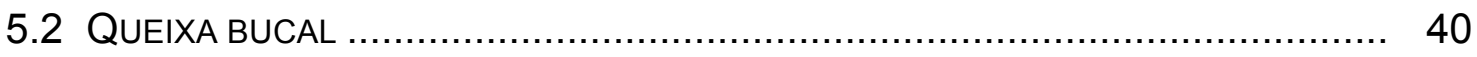

5.3 EXAME FÍSICO ODONTOLÓGICO ....................................................... 42

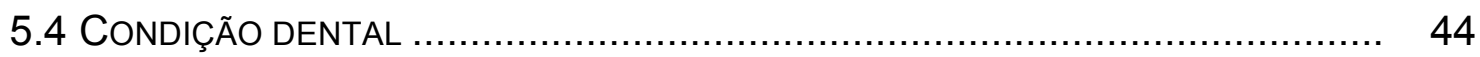

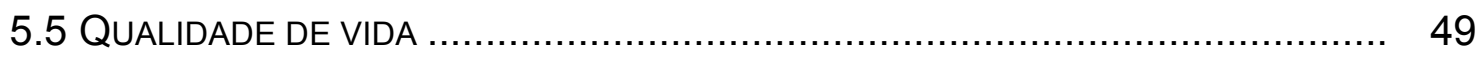

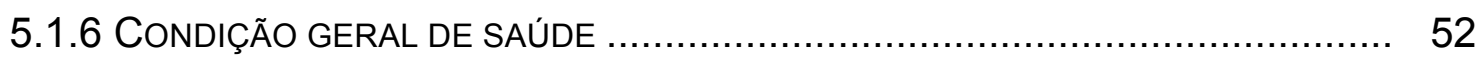

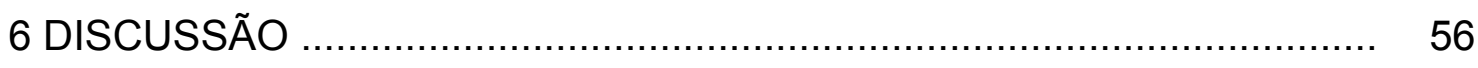

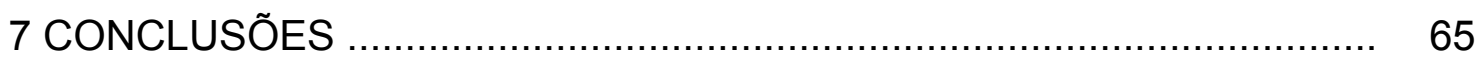

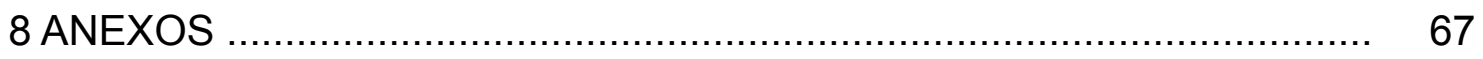

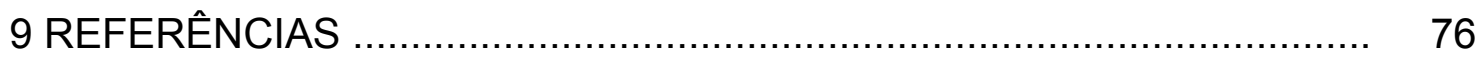

APÊNDICES 
Para Tânia, Mariana e Andre 
Ao meu orientador Dr. José Tadeu Tesseroli de Siqueira, primeiramente por ter aceitado o desafio de mergulhar nesse universo novo, pelo exemplo de mestre e professor, incentivando à busca constante de conhecimento, sempre respeitando seus orientados.

À Dra Silvia Maria de Macedo Barbosa, por ter me mostrado o valor da abordagem paliativa, muito além dos livros, sempre com muito bom humor; e a toda equipe de dor e cuidados paliativos do Instituto da Criança do Hospital das Clínicas da Faculdade de Medicina da Universidade de São Paulo, pela dedicação constante aos pacientes, em especial à Dra Eva Fabiana Sendin, da qual me tornei grande admiradora e amiga.

À Dra Cynthia Savioli, grande incentivadora e participante ativa, desde a elaboração do projeto à finalização da tese, sempre disposta a ajudar e com sugestões valiosas.

À minha querida amiga Sumatra Melo da Costa Pereira Jales, pelas demonstrações constantes de amizade ao longo desses anos, sempre presente e com palavras carinhosas nos momentos de dúvidas e angústias.

Ao Dr. Luiz Alberto Soares Valente Júnior, pela amizade, ensinamentos e troca de experiências.

À minha mãe Tânia Lemos e à minha irmã Mariana Carrillo Negrão, pelo amor e apoio incondicionais, e à minha família, pela torcida constante. 
Ao Andre Faiman, pelo amor e companherismo, sempre comemorando minhas vitórias. Minhas vitórias serão sempre nossas...

Aos pacientes, exemplos de superação e batalha diária pela vida. 
"Cada pessoa que passa em nossa vida, passa sozinha, é porque cada pessoa é única e nenhuma substitui a outra. Cada pessoa que passa em nossa vida passa sozinha e não nos deixa só porque deixa um pouco de si e leva um pouco de nós. Essa é a mais bela responsabilidade da vida e a prova de que as pessoas não se encontram por acaso." Charles Chaplin 
Carrillo CM. Necessidade de cuidados paliativos odontológicos em crianças com doenças crônicas. Caracterização de amostra [Dissertação]. São Paulo: Faculdade de Medicina, Universidade de São Paulo; 2011.

INTRODUÇÃO: A epidermólise bolhosa é uma doença sistêmica crônica que afeta profundamente a qualidade de vida do paciente e cujas manifestações bucais comprometem as atividades diárias corriqueiras, como mastigar, engolir e escovar os dentes. Crianças com câncer também podem ter manifestações bucais, entretanto estas, embora graves, são transitórias e geralmente não afetam os dentes. OJETIVOS: Avaliar a saúde bucal e a necessidade de atenção odontológica em crianças que se encontram em cuidados paliativos devido a uma doença sistêmica crônica não-oncológica, a epidermólise bolhosa, comparativamente com crianças em cuidados paliativos com câncer MÉTODOs: Vinte e quatro pacientes com epidermólise bolhosa (grupo A) e dezoito pacientes com câncer (grupo B) acompanhados pela equipe de dor e cuidados paliativos foram estudados. A avaliação clínica incluiu: características sóciodemográficas, queixas bucais, avaliação da dor orofacial, avaliação dentária, avaliação da qualidade de vida relacionada às atividades de vida diária e condição de saúde geral. RESULTADOS: Ambos os grupos foram homogêneos em relação à faixa etária e distribuição de gênero. Dormência facial, mobilidade dental, alteração do paladar, e dificuldade de fonação estavam presentes apenas no grupo B. Dificuldade de mastigação, disfagia, engasgos, lábios ressecados, e lesões bucais foram mais freqüentes no grupo $A$ que no grupo $B$, com diferença significante, $p<0,0001, p<0,0001, p=0,002, p<0,0001$ e $p<0,0001$ respectivamente. Observou-se uma maior limitação de amplitude de abertura bucal interincisal, número de dentes cariados, prevalência de cárie, e incapacidade na realização das tarefas dos domínios III (alimentar-se) e VII (apanhar) do questionário de qualidade de vida no grupo A em comparação ao $B$, com diferença significante, $p<0,0001, p=0,0004, p<0,001, p<0,001, p=0,005$ e $p<0,0001$ respectivamente. Ambos os grupos apresentaram acometimento importante da condição de saúde geral. CONCLUSÕES: As crianças com epidermólise bolhosa em cuidados paliativos têm úlceras e bolhas freqüentes decorrentes da doença e de modo crônico, enquanto as crianças com câncer apresentam episodicamente mucosites associadas ao período de tratamento. Também apresentam maior freqüência de queixas bucais, condição de saúde bucal grave, maior limitação de abertura bucal e pior qualidade de vida para as tarefas diárias que os pacientes com câncer.

Palavras-chaves:Cuidados paliativos, Saúde bucal, Doença crônica, Criança, Adolescente 
Carrillo CM. Need of oral palliative care in children with chronic illness. Sample characterization [Dissertation]. São Paulo: Faculdade de Medicina, Universidade de São Paulo; 2011.

INTRODUCTION: Epidermolysis bullosa is a genetic chronic disease that affects the quality of life deeply, whose oral symptoms compromised the daily living activities as chewing, swallowing and teeth brushing. . Children with cancer may also have oral manifestations, but transient and usually do not affect the teeth. This study assessed the oral health and the need of oral care in children in palliative care with epidermolysis bullosa compared to children with cancer. METHODS: Twenty-four patients with epidermolysis bullosa (Group A) and 18 cancer patients (Group B) followed up at the Pain and Palliative Care Outpatient Clinic were studied. Clinical assessment included: clinical characteristics, assessment of orofacial pain, oral health, quality of life according to the activities of daily living and general health status. RESULTS: Face numbness, tooth mobility, taste disturbance and speech difficulties were observed only in group B. Difficult chewing, disfagia, gagging, dry lips, oral lesions were more frequent in group $A$ compared to group $B$, with significant difference, $p<0,0001$, $p<0,0001, p=0,002, p<0,0001$ and $p<0,0001$, respectively. Group A had a greater difficulty opening mouth, number of decay teeth, prevalence of caries and disability regarding the $\mathrm{CHAQ}$ eating (III) and reach (VII) domains than group $B$, with significant difference, $p<0,0001, p=0,0004, p<0,001, p<0,001$, $p=0,005$ and $p<0,0001$, respectively. Both groups showed a significant general health impairment. CONCLUSIONS: Epidermolysis bullosa patients in palliative care had chronic oral blistering and ulcerations, due to disease, more frequently than cancer patients, which had oral mucositis as a side effect of the antineoplasic treatment. They also showed greater oral symptoms, poor oral health, greater open mouth limitation and poor quality of life than cancer patients.

Keywords: Hospice care, Oral health, Chronic disease, Child, Adolescent 


\begin{tabular}{|c|c|}
\hline ACT & $\begin{array}{l}\text { Association for Children with Life Threatening or Terminal Conditions and } \\
\text { their Families }\end{array}$ \\
\hline CHAQ & Chidhood Assessement Questionnaire \\
\hline CPO-D & Índice de saúde dos dentes \\
\hline et al. & e outros \\
\hline EB & Epidermólise bolhosa \\
\hline EBS & Epidermólise bolhosa simples \\
\hline EBJ & Epidermólise bolhosa juncional \\
\hline EBD & Epidermólise bolhosa distrófica \\
\hline EBDD & Epidermólise bolhosa distrófica dominante \\
\hline EBDR & Epidermólise bolhosa distrófica recessiva \\
\hline EUA & Estados Unidos da América \\
\hline FMUSP & Faculdade de Medicina da Universidade de São Paulo \\
\hline $\mathrm{HC}$ & Hospital das Clínicas \\
\hline $\mathrm{ICr}$ & Instituto da Criança \\
\hline LLA & Leucemia linfocítica aguda \\
\hline OMS & Organização Mundial de Saúde \\
\hline $\mathrm{RCPCH}$ & Royal College of Paediatrics and Child Health \\
\hline $\mathrm{SOH}$ & Serviço de Oncohematologia \\
\hline VHS & vírus do herpes simples \\
\hline
\end{tabular}


Figura 1 - Zona da membrana basal ................................................ 15

Figura 2 - Encapsulamento das mãos e contratura dos dedos em paciente com EBDR generalizada ..................................... 19

Figura 3 - Interações entre causas e efeitos da ingestão nutricional inadequada na EB grave .............................................. 20

Figura 4 - Anomalia de desenvolvimento dentário em paciente com

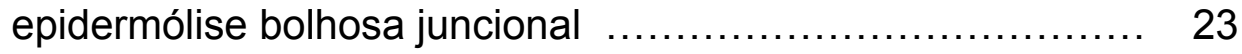

Figura 5 - Alterações bucais em paciente com EBDR ........................... 24

Figura 6 - Condição de saúde bucal de um paciente com EBDR generalizada ....................................................... 26

Figura 7 - Dificuldade de higiene bucal em pacientes com EBDR

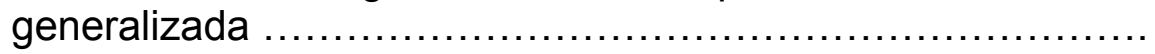


Tabela 1 - Principais tipos e subtipos da Epidermólise Bolhosa ........... 17

Tabela 2 - Características sócio-demográficas dos grupos A e B .......... 39

Tabela 3 - Tipos de tumores da infância e adolescência encontrados no grupo B .............................................................. 40

Tabela 4 - Queixa relacionada à boca nos grupos A e B ............ 41

Tabela 5 - Alterações bucais encontradas ao exame físico intra-oral nos grupos A e B ...................................................... 43

Tabela 6 - Localização e prevalência das lesões bucais (bolhas e fibróticas) identificadas no exame clínico no grupo A ............. 44

Tabela 7 - Avaliação quantitativa da abertura bucal interincisal em milímetros nos grupos A e B............................................. 44

Tabela 8 - Comparação entre os parâmetros C, P e O avaliados concomitamente no grupo A …........................................ 45

Tabela 9 - Comparação entre os parâmetros C, P e O concomitamente no grupo A ........................................................ 46

Tabela 10 - Comparação entre os parâmetros C, P e O concomitamente no grupo B

Tabela 11 - Comparação entre os parâmetros C, P e O e CPOD total entre os grupos A e B ..................................................

Tabela 12 - Dados relacionados ao atendimento odontológico regular e higiene buca nos grupos A e B

Tabela 13 - Comparação entres os domínios do CHAQ e escore total para a qualidade de vida entre os grupos $A$ e B ................... 50

Tabela 14 - Comparação entres os domínios do CHAQ, par a par, nos

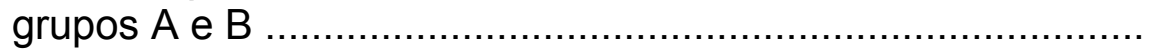

Tabela 15 - Medicação em uso pelos paciente dos grupos A e B 


\section{INTRODUÇÃO}

A boca é uma estrutura ímpar do organismo, pois associa de modo único o meio externo com o interno e tem características anatômicas e fisiológicas específicas, a exemplo do convívio em simbiose com uma vasta microbiota. Nela realizam-se atividades da vida diária indispensáveis aos seres vivos, como alimentação, fala e expressão de sentimentos.

Há muito se sabe também que estruturas da boca, como a mucosa e os dentes, são altamente susceptíveis a alterações da sua homeostase, principalmente quando decorrente de doenças locais ou sistêmicas. A doença cárie é uma delas. É uma das doenças mais comuns que afeta a humanidade, principalmente na infância, podendo felizmente, ser prevenida nos dias atuais. É doença infecciosa de origem multifatorial, cuja consequência inicial é a lesão ao próprio dente, eventualmente sua perda, porém, também pode ter implicações sistêmicas quando afeta a estrutura óssea que contém o dente e torna-se um foco infeccioso. Em crianças com doenças crônicas graves, como a epidermólise bolhosa, a prevenção e o tratamento da cárie tornam-se desafiadores pela agressão da própria doença sistêmica à boca, o que pode contribuir para uma condição de saúde dental muito precária.

A epidermólise bolhosa é uma doença sistêmica crônica que afeta profundamente a qualidade de vida do paciente e cujas manifestações bucais comprometem as atividades diárias corriqueiras, como mastigar, engolir e 
escovar os dentes. Em decorrência, tanto o estado nutricional do indivíduo como a própria prevenção da doença cárie podem ser afetados. As crianças que sofrem dessa doença necessitam atenção permanente à saúde através de cuidados paliativos. Entretanto, nem sempre, principalmente em países em desenvolvimento, recebem a atenção odontológica necessária, seja preventiva, curativa ou mesmo paliativa.

Crianças em tratamento de doenças oncológicas também podem ter manifestações bucais, entretanto estas, embora graves, são transitórias e geralmente não afetam os dentes. Ao contrário, crianças com doenças crônicas como a epidermólise bolhosa necessitaram de cuidados permanentes. Esses dois tipos de doenças, não-oncológica crônica e oncológica, certamente necessitam de estratégias específicas para enfrentar os problemas relacionados à boca, entretanto a literatura cientifica atual ainda é carente de estudos sobre a prevalência dos problemas que afetam a saúde bucal nessas condições específicas, principalmente quando a doença é benigna e crônica.

Acrescente-se, que tanto na cárie como nas manifestações bucais de doenças sistêmicas que afetam a mucosa, a dor é o principal sintoma. Esta, independente de sua causa é multidimensional em sua percepção e afeta física e emocionalmente o indivíduo que a sente.

Portanto, é fundamental conhecer as características gerais e a condição bucal de crianças com doenças crônicas que necessitam permanentemente de cuidados paliativos, inclusive para que a odontologia contribua com protocolos que minimizam o sofrimento dessas crianças. 


\section{OBJetivos}

Avaliar a saúde bucal e a necessidade de atenção odontológica em crianças que se encontram em cuidados paliativos devido a uma doença sistêmica crônica não-oncológica, a epidermólise bolhosa, comparativamente com crianças em cuidados paliativos devido a doenças oncológicas.

Esse objetivo abordará os seguintes tópicos:

1- Caracterizar as amostras.

2- Avaliar a freqüência de queixas bucais, incluindo a dor, nas amostras.

3- Avaliar a condição de saúde bucal dos dois grupos.

4- Avaliar a qualidade de vida dos pacientes nos dois grupos. 


\section{REVISÃo dE LITERATURA}

\subsection{CuIDAdos Paliativos}

A Organização Mundial de Saúde (OMS, 2002) conceitua cuidado paliativo como a abordagem para a melhoria da qualidade de vida dos pacientes e dos seus familiares no enfrentamento de doenças que oferecem risco de vida, através da prevenção e alívio do sofrimento. Isto significa a identificação precoce e o tratamento da dor e outros sintomas de ordem física, psicossocial e espiritual.

\subsubsection{CuIdAdos Paliativos EM PEDIATRIA}

O cuidado paliativo em pediatria é uma abordagem multidisciplinar que procura melhorar a qualidade de vida das crianças e suas famílias e envolve não só o controle e alívio dos sintomas, mas também o cuidado psicossocial, espiritual e suporte durante o luto (OMS, 2002; Hutchinson et al., 2003).

Os cuidados paliativos pediátricos localizam-se entre dois campos de atuação médica bem estabelecidos - a pediatria e os cuidados paliativos em adultos. Desta forma, pode adquirir e contribuir com conhecimento e experiências de ambas as áreas (Lenton et al., 2006).

Enquanto os cuidados paliativos em crianças se desenvolvem e esclarecem seu papel, podem ocorrer algumas dificuldades sobre sua atuação como especialidade. Alguns pediatras não compreendem a contribuição dos 
cuidados paliativos aos seus pacientes, e outros podem falhar ao reconhecer suas próprias limitações em promovê-los (Hutton et al., 2006; Lenton et al. 2006). Por outro lado, os profissionais envolvidos com os cuidados paliativos em adultos não conhecem as necessidades especiais das crianças e suas famílias, por isso, a importância de uma especialidade que as domine (Hutchinson et al., 2003).

Há alguns fatores em comum entre os cuidados paliativos em adultos e crianças como a ameaça de vida, o impacto dos sintomas na vida diária, impacto emocional e angústia das famílias (Lenton et al., 2006). Os cuidados paliativos em crianças diferem dos adultos em diversos aspectos como a variedade de doenças (muitas raras e de caráter familial), diferentes prognósticos, muitas vezes incertos, local de promoção dos cuidados, avaliação e manejo dos sintomas, aspectos éticos, maior envolvimento e sofrimento dos cuidadores e pelo contínuo desenvolvimento físico, emocional e cognitivo da criança (Goldman, 1998; Lenton et al., 2006).

Esses cuidados podem ser necessários desde a infância e permanecem por muitos anos em algumas crianças, e em outras, apenas quando mais velhas e por um curto período (Goldman, 1998).

O diagnóstico vai direcionar o tipo de cuidado que a família e a criança necessitarão. Além disso, fatores relacionados ao desenvolvimento da criança vão influenciar desde a fisiologia e farmacocinética, a compreensão da doença e morte, assim como em sua comunicação e participação nas decisões (Association for Children with Life-Threatening or Terminal Conditions and their 
Families/ Royal College of Paediatrics and Child Health, 1997; Goldman, 1998; American Academy of Pediatrics, 2000; Yates, 2006).

Os cuidados paliativos em adultos estão tradicionalmente concentrados em pacientes oncológicos, no entanto o câncer é apenas uma das diversas doenças que limitam a vida na infância (Hutchinson et al.,2003). Crianças com doenças não-oncológicas que limitam a vida podem sobreviver por muitos anos ou até mesmo décadas, com necessidades médicas complexas, prévias a uma morte prematura. Além disso, durante o curso da doença podem apresentar diversos episódios em que a morte parece iminente e recuperar-se, até o próximo episódio (Hutchinson et al., 2003; Hyson, 2006).

São consideradas doenças que limitam a vida na infância qualquer doença ou condição que se desenvolva na infância (antes de 19 anos) pela qual a criança provavelmente (probabilidade maior 50\%) morra prematuramente (antes de 40 anos), ou qualquer condição desenvolvida na infância que sem maiores intervenções (que por si apresentam alta mortalidade), a criança morra prematuramente. Doenças agudas, traumas, doenças mentais e de curto prazo estão excluídas (Lauer e Camitta, 1980 citado por Lenton et al., 2006) ${ }^{1}$.

Desta maneira, quatro grupos principais de doenças que limitam a vida em crianças foram identificados pela Association for Children with Life Threatening or Terminal Conditions and their Families (ACT) e o Royal College of Paediatrics and Child Health (RCPCH), em 1997: (1) doenças para qual o tratamento curativo é possível, mas pode falhar (ex.: câncer; excluídas crianças

\footnotetext{
${ }^{1}$ Lauer ME, Camitta BM. Home care for dying children: a nursing model. Pediatrics. 1980; 1032-5.
} 
em manutenção por longo período); (2) doenças nas quais a morte prematura é esperada, mas o tratamento intensivo pode prolongar a vida com qualidade (ex.: fibrose cística); (3) doença progressiva para qual o tratamento é exclusivamente paliativo e pode se estender por anos (ex.: epidermólise bolhosa); e (4) condições com deficiências neurológicas que embora não sejam progressivas induzem a vulnerabilidade e complicações que podem levar a morte prematura (ex.:paralisia cerebral grave).

Em estudo retrospectivo, por meio de banco de dados de atestados de óbito, realizado nos EUA para identificar quantas crianças morreram devido a condições crônicas complexas (CCC) de 1979 e 1997, Feudtner et al. (2001) observaram que das 1,75 milhões de mortes, $5 \%$ foram por câncer, $16 \%$ por doenças não-oncológicas, 43\% traumas e 37\% por outras causas.

Em relação a doenças não-oncológicas que limitam a vida, a mortalidade é de 1,5 por 1000 crianças e jovens de 0 a 19 anos. Em países desenvolvidos, a incidência anual de morte nessas condições é de 1: 10.000 (Lenton et al., 2006).

Dependendo do diagnóstico, algumas crianças permanecem na fase de transição por anos ou até mesmo décadas, como em crianças prematuras, com fibrose cística e HIVIAIDS avançada (Hutton et al., 2006). Em crianças com câncer, nem sempre é possível determinar quando a doença irá responder a terapia oncológica, assim como a trajetória do processo de morte (Hyson, 2006). 
Também se faz necessário distinguir o cuidado paliativo do cuidado terminal em crianças. O cuidado terminal faz parte do cuidado paliativo, porém relacionado aos cuidados oferecidos nas últimas semanas de vida. O objetivo é preparar psicologicamente e espiritualmente a criança e a família para a morte, concomitantemente ao controle dos sintomas da doença, porém de maneira mais intensa, para criança permanecer o mais confortável possível (Hutchinson et al., 2003).

Para a promoção dos cuidados paliativos em pediatria é necessária uma equipe multidisciplinar bem integrada e funcional para total acesso e cuidados às múltiplas necessidades das crianças, assim como de sua família (Hutton et al., 2006), geralmente composta por médicos, enfermeiros, psicólogos, membros da capelania, assistentes sociais e voluntários $(\mathrm{ACT} / \mathrm{RCPCH}, 1997$; Goldman, 1998; Barbosa, 2003), mas o número de profissionais que a família terá contato e a complexidade da equipe dependerá das necessidades particulares de cada família (Jassal e Sims, 2006).

Para este estudo serão revisados dois tipos de doenças que exigem cuidados paliativos: oncológicas e não-oncológicas (aqui representadas pela epidermólise bolhosa)

\subsubsection{DOENÇAS ONCOLÓGICAS}

No Brasil, são estimados mais de 9.000 novos casos anuais de câncer infanto-juvenil. Esta estimativa corresponde à maior causa de mortalidade por doença na faixa etária de 1 a 19 anos sendo, no geral, inferior apenas àquelas 
decorrentes de acidentes e violência (INCA, 2009). Aproximadamente $22 \%$ das crianças com câncer morrerão devido a doença, o que torna o câncer a maior causa de morte não-acidental na infância.

O câncer na infância, embora seja um evento raro, em termos de número absoluto, merece consideração especial não só pelo desgaste psíquico e social que acarreta, mas pelos altos custos financeiros envolvidos no diagnóstico, tratamento e atendimento às seqüelas. Causa um impacto enorme na criança, em seus pais e no ambiente em que vive (Mirra et al., 2004).

Cabe destacar que os tipos de tumores que ocorrem em menores de 15 anos são totalmente diferentes daqueles que acontecem nos adultos. Nas crianças há o predomínio de leucemias, linfomas, tumores dos sistemas nervosos central e do simpático, rabdomiossarcomas, tumores de Wilms, retinoblastomas e tumores ósseos, enquanto que nos adultos predominam tumores de pulmão, estômago, intestino, próstata e mama (Braga et al., 2002).

A literatura relata que na infância a leucemia linfóide aguda (LLA) é a mais frequente representando $24 \%$ de todos os tipos de neoplasias (Ministério da Saúde, 1997; Smith e Ries, 2002; Balis et al., 2002) e 75\% das várias leucemias (Margolin, 2002).

Quanto à questão etária, o período de 0 a 4 anos é citado como o mais propenso a desenvolver um câncer, embora linfomas, carcinomas e tumores ósseos ocorram mais entre 10 e 14 anos (Mirra et al., 2004; Hong e da Fonseca, 2008). No Brasil quando se correlaciona a idade com a natureza do tumor observa-se que entre 1 e 4 anos são as leucemias que predominam 
(31,6\%); entre 15 e 18 são os linfomas (35,6\%) e que entre $1-4 ; 5-9$ e 10-14 anos, os tumores do sistema nervoso central têm incidência semelhante (26\%) (INCA, 2009).

Já em relação à comparação entre gêneros em estudos de nosso meio (Mirra et al., 2004) ou internacionais há concordância de maior prevalência no sexo masculino tanto para tumores em geral, como para as leucemias, linfomas e tumores do sistema nervoso central.

\subsubsection{MANIFESTAÇÕES BUCAIS DAS DOENÇAS ONCOLÓGICAS}

As infecções bucais e dentais podem complicar o tratamento oncológico, assim como postergá-lo, o que leva à um aumento da morbidade e diminuição da qualidade de vida das crianças (da Fonseca, 2004). Portanto, a avaliação odontológica deve ser realizada o mais precocemente possível para que os cuidados adequados sejam realizados, se possível, anterior ao início da terapia antineoplásica (da Fonseca, 2004).

Mucosite, parotidite, alterações no paladar, xerostomia, infecções oportunistas, dor, neuropatias, sangramento e trismo são as complicações agudas mais comuns decorrentes do tratamento quimioterápico e radioterápico. Essas complicações, se graves, requerem terapias de suporte e podem ser um fator dose limitante ao tratamento (Hong e da Fonseca, 2008).

O manejo da dor bucal é um componente importante no cuidado do paciente oncológico. A mucosite bucal é uma das complicações mais comuns 
decorrentes da terapia contra o câncer (Epstein et al., 2001), e considerada a pior experiência sofrida pelos pacientes (Cheng, 2009).

Inicialmente são caracterizadas por lesões eritematosas, sensação de ardência, seguida de inflamação e subseqüente ulceração, com a presença ou não de pseudomembrana, seguida de sintomatologia dolorosa intensa que leva a dificuldade na mastigação, fala e deglutição observado principalmente nos quadros mais graves (Scully et al., 2004; Sonis, 2004; Sonis, 2009). Por essa razão, leva à diminuição da qualidade de vida, além de aumentar a morbidade, tempo de hospitalização, custos hospitalares e muitas vezes a diminuição ou até mesmo a interrupção do tratamento com impacto negativo na evolução e prognóstico da doença (Sonis et al., 2001; Cella et al., 2003; Sonis et al., 2004).

O suporte analgésico tem sido o foco dos cuidados de suporte no controle dos sinais e sintomas da mucosite bucal, no entanto, a dor continua sendo um problema terrivelmente difícil para os pacientes que a experimentam, e que continua presente, apesar do uso significante de ópioides (Cheng, 2009).

Para muitas crianças, a mucosite bucal causa altos níveis de sofrimento psicológico associados às intensas e debilitantes perdas da função bucal e experimentam uma variedade de emoções, como infelicidade, raiva, e choro, relacionados aos seus sintomas e sofrimentos (Cheng, 2009).

A imunossupressão decorrente das terapias antineoplásicas predispõe às crianças a infecções oportunistas como herpes simples, candidose, gengivite ulcerativa necrotizante, assim como, a uma rápida progressão da doença 
periodontal (Fayle e Curzon, 1991; Fayle et al., 1992; Cousin, 1997; Da Fonseca, 2004).

A candidose bucal é responsável pela maioria das infecções oportunistas superficiais e profundas em pacientes neutropênicos. Diagnóstico precoce e o tratamento imediato são cruciais, já que a mesma pode progredir rapidamente para uma infecção sistêmica, com altas taxas de mortalidade (Hong e da Fonseca, 2008).

A infecção viral mais comum em crianças em terapia oncológica é causada pelo vírus herpes simples (VHS) (Hong e da Fonseca, 2008). Essa infecção frequentemente ocorre pela reativação do vírus latente em um indivíduo previamente infectado. O diagnóstico dessa infecção pode ser difícil em alguns pacientes por ser facilmente confundido com a mucosite bucal (Hong e da Fonseca, 2008).

Em relação às infecções bacterianas, apesar de poderem envolver qualquer superfície da mucosa, a gengiva é o local mais comumente afetado. Nos casos em que a infecção não é diagnosticada e tratada adequadamente, a mesma pode causar episódios febris em pacientes imunossuprimidos, e nos casos graves, bacteremia sistêmica (da Fonseca, 2004).

A incidência de sangramento relatados em crianças em tratamento oncológico varia de $6 \%$ a $42 \%$, e frequentemente são resultantes de trombocitopenia. O sangramento na maioria das vezes é proveniente do tecido gengival e pode ser exacerbado por uma higiene bucal deficiente. Sangramento 
espontâneo é raro se a contagem de plaquetas estiver maior que 50,000 mil/mm (da Fonseca, 2004).

Alguns pacientes podem relatar odontalgia, mimetizando uma pulpite irreversível, na ausência de infecção dental ou periodontal. Este fato pode ser tanto decorrente dos efeitos adversos da vincristina e vinblastina, agentes quimioterápicos comumente usados, como por infiltrado leucêmico (Ayers e Colquhoun, 2000; Da Fonseca, 2004). Também podem causar neuropatia do trigêmio e facial, manifestando-se clinicamente como dor paroxística, parestesia e fraqueza dos músculos faciais, em que após a suspensão do uso, os sintomas costumam desaparecer (Ayers e Colquhoun, 2000).

A xerostomia pode estar presente e constitui uma preocupação pela sua importância na manutenção da saúde bucal, podendo levar à complicações bucais importantes, dentre elas: cárie dentária, candidose, queilite angular, mucosite, disgeusia, halitose, glossite, lesões traumáticas, infecções, comprometimento nutricional, aumento da intolerância à medicações, disfunção esofágica, e dificuldade na mastigação e fonação (Sweeney e Bagg, 1995; Paunovich et al., 2000; Jensen et al., 2003; Cohen-Brown e Ship, 2004; Haveman, 2004).

Lábios ressecados se não hidratados, podem levar a formação de grandes fissuras que podem ser infectadas por bactérias provenientes da boca (Ktywulak, 1992). 


\subsubsection{EPIDERMÓLISE BOLHOSA}

Epidermólise bolhosa (EB) é um grupo heterogêneo e raro de doenças bolhosas da pele, determinadas geneticamente (Haynes, 2006). É caracterizada pela extrema fragilidade da pele e mucosa, com formação recorrente de bolhas, em resposta à uma fricção diária mínima, ao trauma e ao calor (Gannon, 2004; Watterson et al., 2004; Haynes, 2006).

Geralmente apresenta padrão de hereditariedade recessivo ou dominante (Marini e Vechiet, 2001; Haynes, 2006), no entanto, também pode ser resultado de mutações gênicas espontâneas, sem história familiar (Haynes, 2006). Essas mutações alteram a formação das proteínas estruturais na junção epiderme-derme/zona da membrana basal, onde a estrutura enfraquecida, ou a ausência de estruturas, levam facilmente a separação das camadas da pele e consequentemente à fragilidade (Uitto e Pulkkinen, 2000; Uitto et al., 2000).

As formas recessivas são as mais graves, e apesar da grande variedade em relação à gravidade nesse grupo, as taxas de morbidade e mortalidade são altas (Fine et al., 2004).

A EB foi descrita pela primeira vez como entidade única por von Hebra em 1870. A ocorrência é mundial, afeta ambos os gêneros igualmente, assim como todos os grupos raciais e étnicos. Mundialmente, uma em cada 17.000 nascidos vivos será uma criança com EB (Haynes, 2006).

Os efeitos da EB variam da morte precoce na infância nos casos mais graves, à pacientes que experimentam uma vida de crescentes deficiências. 
Nas formas mais leves, uma vida normal é esperada, apesar da presença de algum tipo de deficiência e dor na maioria dos pacientes (Fine et al., 2004).

A EB é classificada de acordo com o local em que a separação tecidual ocorre (figura 1). A classificação mais recente reconhece quatro categorias principais: simples, juncional, distrófica e síndrome de Kindler (Athernon e Denyer, 2003; Pillay, 2008), que variam de acordo com a gravidade (tabela 1). Incluem aproximadamente 23 variações, manifestadas por um espectro de apresentações clínicas.

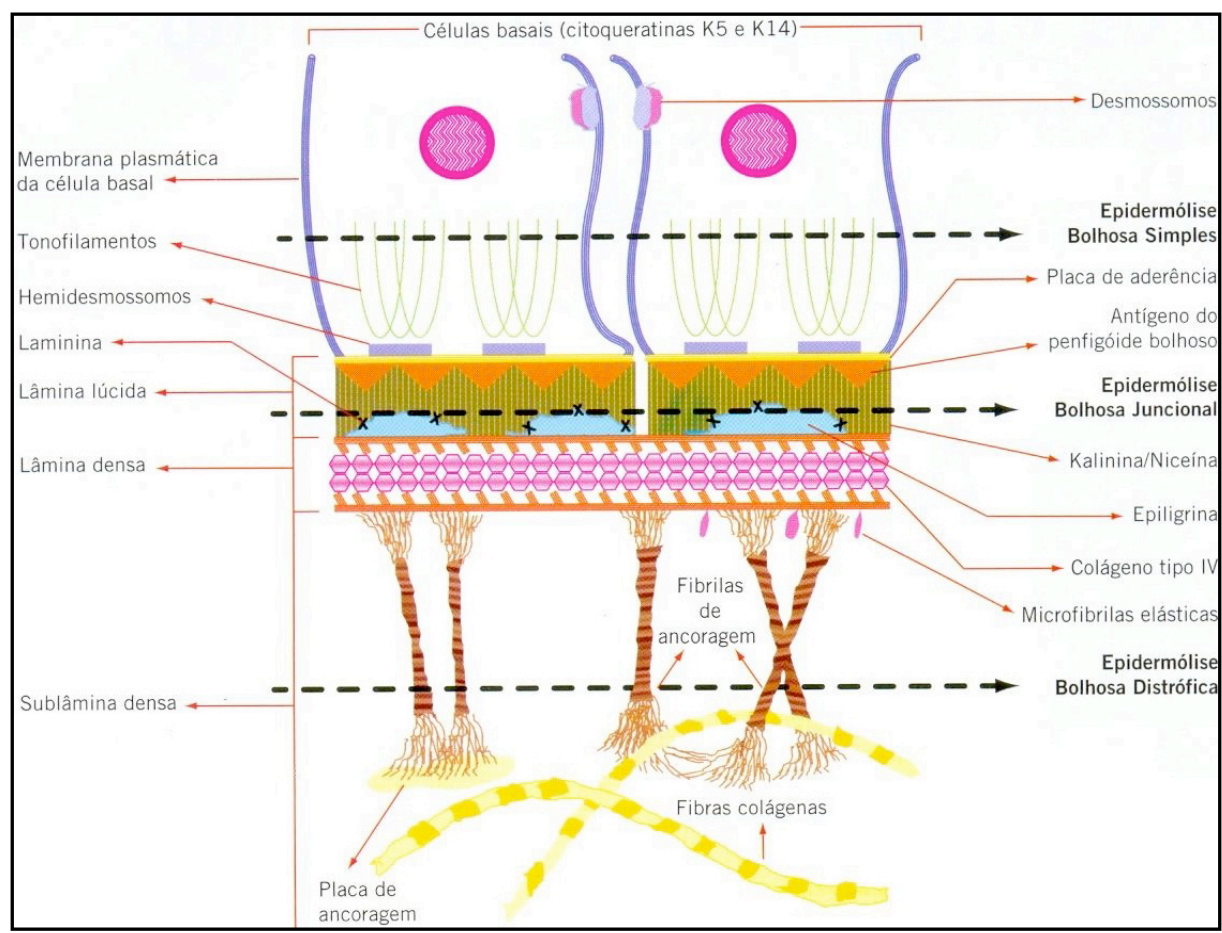

Figura 1. Zona da membrana basal. Representação esquemática das estruturas teciduais envolvidas nos três tipos principais de EB (Moscardi et al., 2005) 
A EB simples (EBS) é a forma mais comum e superficial da doenca, e ocorre devido a mutações nos genes que codificam as queratinas 5 e 14. A formação das bolhas e a separação tecidual ocorrem na epiderme nos queratinócitos da membrana basal, e a cicatrização ocorre sem fibrose, no entanto pode levar a hiperpigmentação generalizada (Sprecher, 2010).

Apesar da fragilidade extender-se por toda a pele, a formação de bolhas ocorre mais frequentemente nas áreas expostas ao atrito, isto é, mãos e pés (Pillay, 2008), podendo também ser precipitada pelo calor (Atberton e Denyer, 2003; Pillay e Graham-King, 2007). Esta forma é predominantemente autossômica dominante, e é praticamente compatível com uma vida normal (Atberton e Denyer, 2003; Pillay e Graham King, 2007).

As formas juncionais são causadas por mutações nos genes responsáveis pela função da laminina 322, importante na adesão celular da membrana basal. Existem duas formas principais, a EBJ Herlitz que leva comumente a morte durante a primeira infância, e a EBJ não-Herlitz que geralmente é compativel com a vida (Atberton e Denyer, 2003).

É predominantemente recessiva e a separação tecidual ocorre na lâmina lúcida na zona da membrana basal (Atherton e Denyer, 2003). As alterações mais comums são áreas de ulceração crônica, distrofia das unhas, erosões nas córneas, fibroses cicatriciais, alopécia e problemas dentais, como os defeitos de esmalte (Pai e Marinkovich, 2002; Fine et al., 2004).

Os tipos de EB distrófica (EBD) são causadas por mutações no colágeno tipo VII que codifica a ancoragem das fibrilas localizadas abaixo da lamina basal 
na zona dermo-epidermal da membrana basal, em que a gravidade está relacionada a quantidade e funcionabilidade da ancoragem das fibrilas presentes (Wright, 2010).

Na EBD dominante (EBDD), a pele e mucosa são afetadas de maneira mais leve que na forma recessiva, e muitos pacientes vivem uma vida próxima do normal. Já os pacientes com EBD recessiva (EBDR) frequentemente apresentam feridas com maiores extensões na superfície corpórea e envolvimento de mucosas e olhos (Fine et al., 2000).

A EB distrófica clássica ou EBDR generalizada resulta em múltiplas complicações. Há uma tendência para formação de bolhas e feridas com fibrose cicatricial que levam ao desenvolvimento de contraturas. Apesar da morte não ser comum na lactância, as contraturas levam a uma incapacidade progressiva e permanente (De Benedittis et al., 2004).

Tabela 1 - Principais tipos e subtipos da Epidermólise Bolhosa

\begin{tabular}{|c|c|c|}
\hline Tipos principais & Subtipos principais & Proteínas alvo \\
\hline EB simples & $\begin{array}{l}\text { EBS suprabasal } \\
\text { EBS basal }\end{array}$ & $\begin{array}{l}\text { Placofilina-1; } \\
\text { desmoplaquina ?; outras } \\
\text { Queratina } 5 \text { e } 14 \text {; plectina; } \\
\text { integrina } \alpha 6 \beta 4\end{array}$ \\
\hline EB juncional & $\begin{array}{l}\text { EBJ Herlitz } \\
\text { EBJ não-Herlitz }\end{array}$ & $\begin{array}{l}\text { Laminina-332 (laminina-5) } \\
\text { Laminina-332; colageno } \\
\text { tipo XVII; integrina } \alpha 6 \beta 4\end{array}$ \\
\hline EB distrófica & $\begin{array}{l}\text { EBD dominante } \\
\text { EBD recessiva }\end{array}$ & $\begin{array}{l}\text { Colágeno tipo VII } \\
\text { Colágeno tipo VII }\end{array}$ \\
\hline Síndrome de Kindler & ------- & Kindlin-1 \\
\hline
\end{tabular}

Fine et al. (2008) 
As crianças com EB apresentam uma variedade de sintomas decorrentes do acometimento de diversos órgãos e sistemas do organismo (Fine e Melleiro, 2009a; Fine e Melleiro, 2009b).

A complicação músculo-esquelética mais significante é o progressivo encapsulamento e contracturas das mãos e pés (deformidades em luva) (Figura 2). Outras complicações como osteopenia e osteporose (Fewtrell et al., 2006), e a distrofia muscular podem ser observadas (Fine e Melleiro, 2009b).

O envolvimento gastrointestinal é comum e resulta em considerável morbidade, incluindo grave comprometimento nutricional, podendo contribuir para um retardo profundo do crescimento (Freeman et al., 2008, Fine et al., 2008b; Fine e Melleiro, 2009a). A constipação aparece quando a defecação é dolorosa pela formação de bolhas e fissuras na região perianal, que leva à retenção das fezes, associado à uma alimentação pobre em fibras, à disfagia e às dificuldades na mastigação, exacerbando o quadro (Fine et al. 2008a; Freeman et al., 2008).

Infecções cutâneas e sistêmicas, podem levar a morbidade e mortalidade, assim com o comprometimento da reparação das feridas (Fine e Melleiro, 2009b). Anemia grave, principalmente pela deficiência de ferro, leva a fadiga e redução, falta de ar, pobre cicatrização das feridas e a anorexia (Fine e Melleiro, 2009b).

Outras sequelas importantes da EB grave incluem atraso da puberdade, falta de auto-estima, percepção alterada da imagem corporal, depressão, ideação suicida, e quebra da unidade familiar (Fine e Melleiro, 2009b). 
A dor é constante na vida da maioria dos pacientes com EB (Fine at al. 2004; van Scheppingen et al. 2008). É individual e abrange os aspectos físico, social, cultural e emocional (Watterson et al., 2004). As fontes de dor aguda podem ser pelas bolhas e/ou feridas, refluxo gastro-esofágico, dentes, úlceras nas córneas, fissuras anais e tarefas diárias como se vestir e tomar banho (Watterson et al., 2004; Freeman et al., 2008). Já a dor crônica é decorrente de constipação, contraturas, osteoporose e pode ser inflamatória ou neuropática (Watterson et al., 2004).

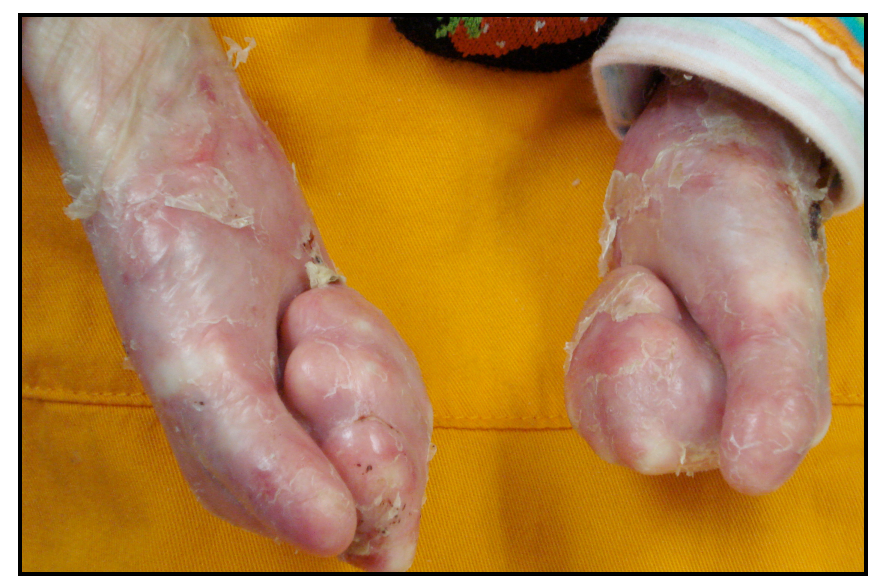

Figura 2. Encapsulamento das mãos e contratura dos dedos em paciente com EBDR generalizada. Mãos em luvas de boxe ("Mitten deformities").

Como até o momento não há cura para EB, as bases do cuidado desses pacientes são controle de infecções, manejo das feridas, alívio da dor, promoção de um estatus nutricional adequado, intervenção cirúrgica e promoção de uma qualidade de vida melhor possível (Haynes, 200 


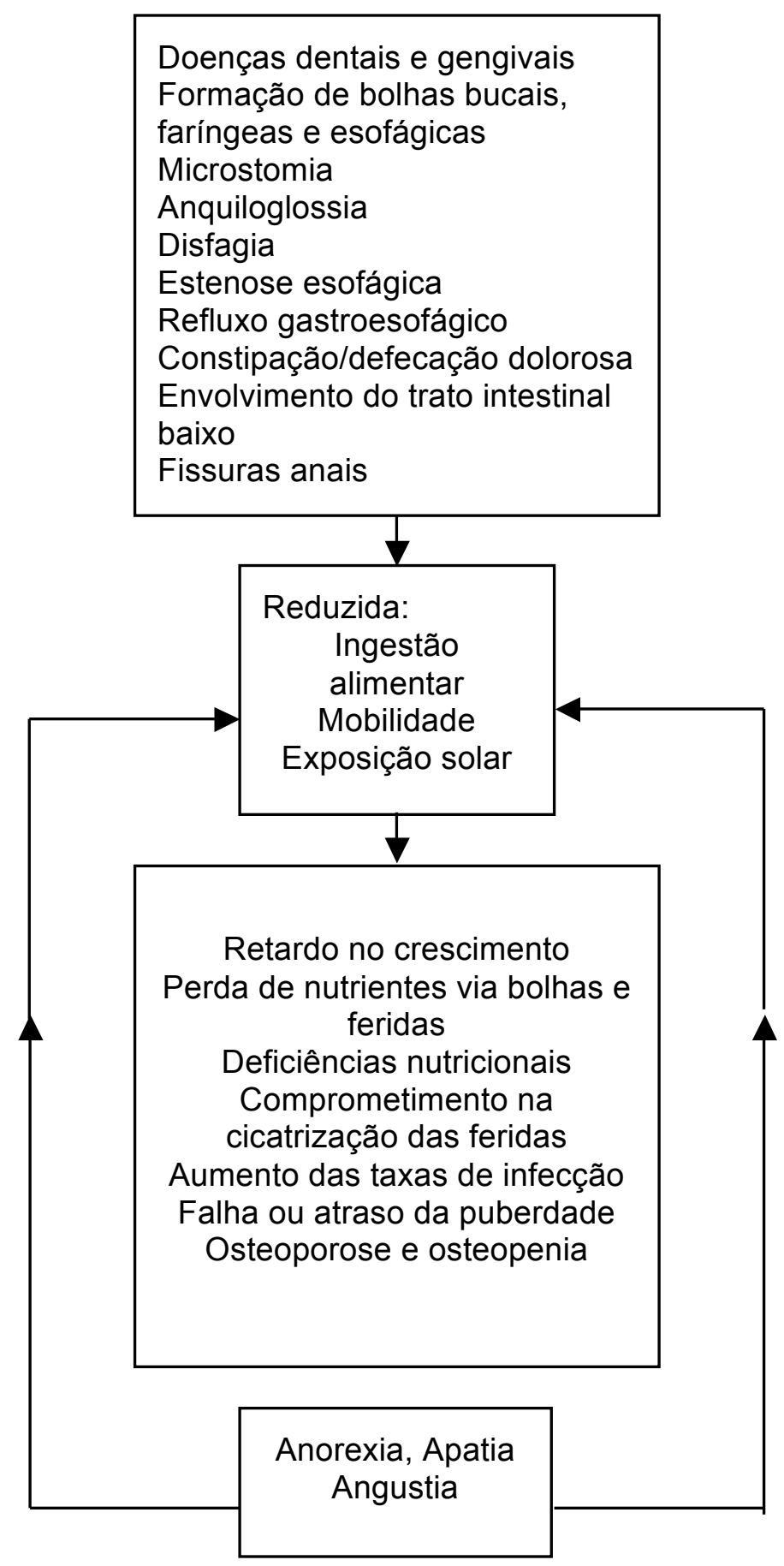

Figura 3. Interações entre causas e efeitos da ingestão nutricional inadequada na EB grave (Haynes, 2006) 


\subsubsection{MANIFESTAÇÕES BUCAIS DA EPIDERMÓLISE BOLHOSA}

As manifestações craniofaciais e bucais variam em carácter e gravidade dependendo do tipo de EB considerado (Wright, 2010). Os tecidos afetados e o fenótipo apresentado estão intimamente relacionados às proteínas específicas anormais ou ausentes resultantes das mutações genéticas causadas por essas desordens (Wright e Fine, 1993; Wright, 2010).

Como a EBS é causada por mutações que causam clivagem intraepidérmica na pele e os mesmos também são expressos pela mucosa bucal, (Fine et al., 2008a), esses pacientes também apresentam fragilidade dessa mucosa aumentada, com alta porcentagem de formação de bolhas e ulcerações.

$\mathrm{Na}$ maioria dos casos, as lesões são localizadas e ocorrem secundariamante ao trauma ou a manipulação tecidual, no entanto sem fibrose cicatricial (Wright et al., 1991). Por outro lado, dependendo da gravidade, alguns podem apresentar bolhas na boca e envolvimento significante da mucosa bucal, com alguma fibrose cicatricial (Wright, 2010). A dentição tende a formar-se normalmente (Wrigth et al.1993) e a prevalência de cárie nesses indivíduos é semelhante a da população não afetada pela doença (Wright et al., 1994).

As proteínas trancritas pelos genes afetados na EBJ são importantes na adesão celular epitelial na mucosa bucal e no desenvolvimento do botão dentário (Wright et al., 1994a; Fine et al., 2008b). A fragilidade resultante dessas mutações é variável, mas quase todos os indivíduos apresentam 
aumento da fragilidade da mucosa bucal, acompanhada pela formação de bolhas e ulceração (Sedano, 1989; Wright et al., 1991).

Apesar da alta prevalência de lesões bucais nos diferentes subtipos de EBJ, a maioria não apresenta fibrose cicatricial oral significante, em que a mobilidade dos tecidos moles e a arquitetura bucal permanencem normais (Wright, 2010). Há uma exceção apenas para o subtipo EJ Herlitz, onde há uma granulação exuberante dos tecidos peribucais, levando frequentemente a microstomia e a alguma perda de mobilidade dos tecidos envolvidos (Wright et al., 1991).

Os genes causarores da EBJ são críticos para o desenvolvimento dental. Causam alteração da adesão entre os ameloblastos, essencial para a mineralização do esmalte, levando aos defeitos de esmalte, podendo variar de depressões na superfície à hipoplasia generalizada (figura 4) (Kirham et al., 1996; Kirkham et al., 2000; Wright, 2010). Desta forma, apresentam alto risco de desenvolver lesões cariosas, favorecendo retenção de substrato e crescimento bacteriano, causadores da cárie dentária (Wright et al., 1994; Wright, 2010).

$\mathrm{Na}$ epidermólise bolhosa distrófica, as manifestações nos tecidos bucais no tipo recessivo variam de moderada a extremamente grave (Crawford et al., 1976; Album et al., 1977; Wright et al., 1993). No tipo dominante, a fragilidade da mucosa bucal está presente, porém a formação de bolhas não é freqüente.

Como o colágeno tipo VII é fundamental para manter a integridade da mucosa bucal assim como da pele, os indivíduos com EBDR grave 
generalizada apresentam extrema fragilidade da mucosa peribucal e bucal (Wright, 2010). Este fato é observado logo após o nascimento, as bolhas se formam facilmente em resposta a sucção, podendo interferir na habilidade de sucção do recém-nascido (Fitzpatrick et al., 2001; De Benedittis et al., 2004).

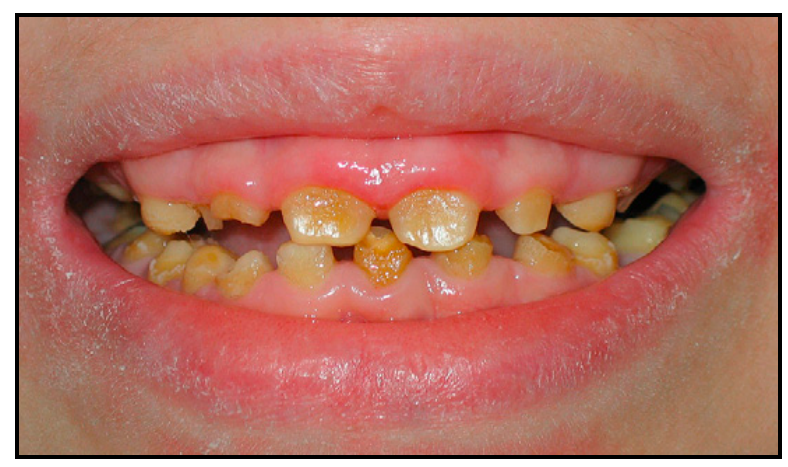

Figura 4. Anomalia de desenvolvimento dentário em paciente com epidermólise bolhosa juncional. Hipoplasia de esmalte generalizada (Kramer, 2010)

As bolhas formam-se em toda extensão do trato gastrointestinal até a orofaringe tornando a alimentação uma experiência desagradável e dolorosa. (Fitzpatrick et al., 2001; De Benedittis et al., 2004; Moscardi et al., 2005). A formação contínua de bolhas e o processo cicatricial (fibroses) resultam em mudanças significantes na arquitetura bucal: (1) a língua torna-se despapilada e fundida ao soalho da boca (anquiloglossia), o que torna a mastigação e a eliminação de resíduos dos dentes dificultada; (2) perda de estruturas anatômicas como as rugosidades palatinas; (3) microstomia; e (4) diminuição ou perda do fundo de sulco com a formação de fibrose tecidual logo abaixo ou 
acima das coroas dos dentes (figura 5) (Fitzpatrick et al., 2001; Watterson et al., 2006 ; Wright, 2010).

Os tecidos bucais envolvidos na abertura bucal não se desenvolvem normalmente pela continua cicatrização, resultando em significante limitação de abertura bucal (Fitzpatrick et al., 2001; Watterson et al., 2006; Wright, 2010). A presença de microstomia significante pode impedir o quanto os indivíduos afetados podem abrir sua boca, limitando dramaticamente a distância entre os dentes, mesmo em abertura máxima (Wright, 2010).

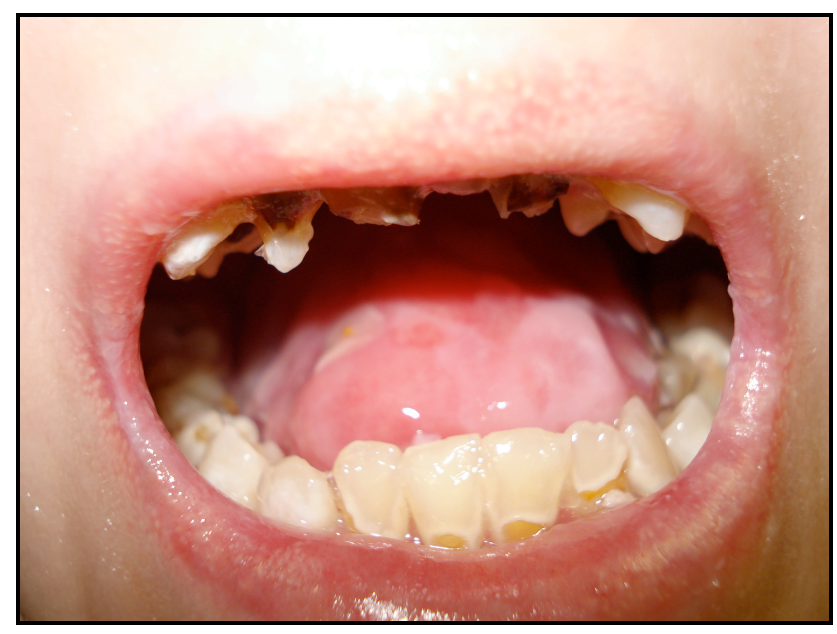

Figura 5. Alterações bucais em paciente com EBDR. Presença de microstomia, múltiplas lesões de cáries ativas, língua despapilada e invadida por lesões.

Em estudo de série de casos para avaliar quantitativamente a microstomia e a prevalência de lesões bucais em pacientes com EBDR, Serrano-Martinez et al. (2003) encontraram uma distancia inter-incisal menor que $30 \mathrm{~mm}$ em $80 \%$ dos pacientes, e nos demais pacientes abertura máxima 
variando entre 31 a $40 \mathrm{~mm}$. Constataram que as seqüelas bucais mais prevalentes foram a microstomia e atrofia do palato (100\%), lesões bolhosas (92\%) em que a língua foi a estrutura mais afetada, anquiloglossia, obliteração do vestíbulo bucal e língua despapilada (80\%). Wright et al. (1991) encontraram uma média de abertura bucal de $33,6 \mathrm{~mm}$ para os pacientes com EBDR e 46,8mm com EBDD (Wright et al. 1991).

O grande envolvimento dos tecidos moles resulta em uma alimentação macia e pastosa, frequentemente calórica, para atender às necessidades nutricionais dos pacientes. Com a constante formação de bolhas, a alimentação tende a ser mais lenta e freqüente. A perda da mobilidade lingual e a diminuição ou perda do fundo de sulco diminui a eliminação de resíduos alimentares, prolongando o contanto entre as às superfícies dentárias e o substrato cariogênico (Wright, 2010). Esses fatores levam ao alto risco e prevalência de cárie dental em indivíduos com EBDR grave generalizada (figura 6).

Além disso, os problemas dentais também são conseqüência principalmente de uma higiene dental inadequada devido à fragilidade da mucosa bucal (figura 7) (Wrigth et al., 1994b; Wright et al., 2003; De Benneditis et al., 2004). 


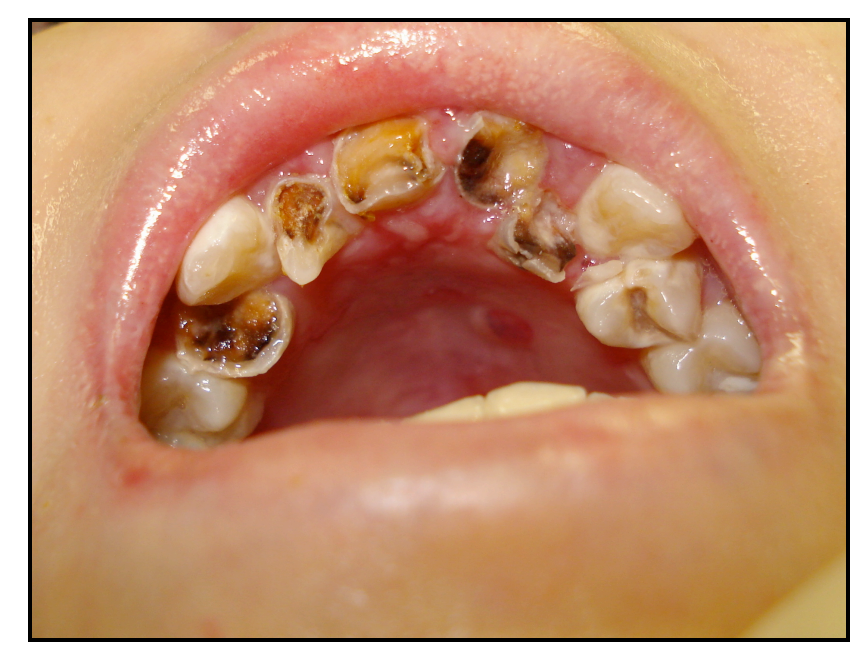

Figura 6. Condição de saúde bucal de um paciente com EBDR generalizada. Múltiplas raízes residuais e lesões por cáries

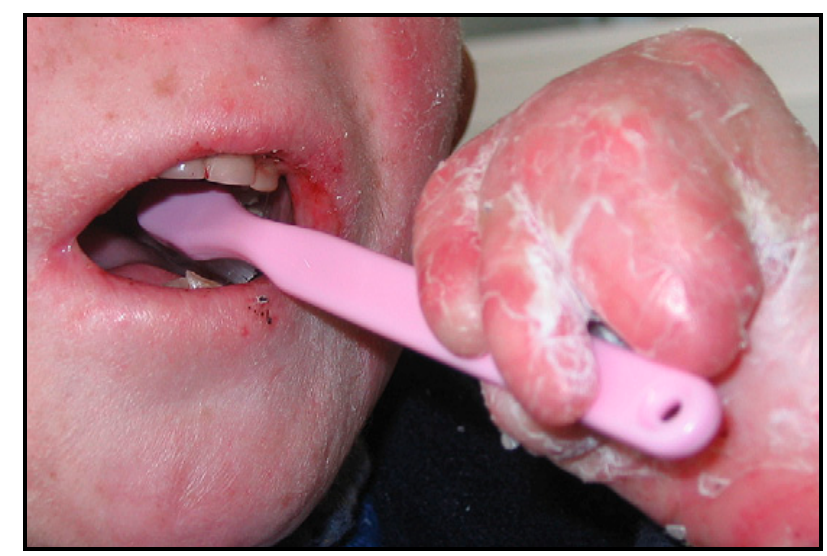

Figura 7. Dificuldade de higiene bucal em paciente com EBDR generalizada (Kramer, 2010). Paciente com EBDR generalizada escovando os dentes apesar da microstomia, observe a fragilidade tecidual e deformidades nas mãos. 


\subsection{Saúde bucal e atenção odontológica em criançAs SOB cuidados PALIATIVOS}

\subsubsection{SAÚdE BUCAL E ATENÇÃo OdONTOLÓGICA}

A idéia de saúde bucal está associada, primariamente, aos dentes e suas estruturas de suporte. Como as cáries dentárias e as doenças periodontais são frequentes na população, e constituem-se em sério problema de saúde pública, elas são alvo da atenção profissional e do sistema público de saúde. Neste sentido, a dor de dente passa a ser o sintoma relevante, não só para o diagnóstico das doenças dos dentes e seus anexos, mas também pelo sofrimento e impacto que causa na vida do paciente, família e do próprio sistema de saúde. A dor de dente simula praticamente todas as demais dores que afetam a face, crânio e pescoço. Previsível na maioria das vezes, variável na sua apresentação clínica, frequentemente mal localizada e difusa, irradiando-se pela face, pelos outros dentes, pela cabeça, pelo pescoço, até atingir braços e tórax; é considerada a mais comuns das dores, e possivelmente a maioria absoluta da população sinta dor de dente alguma vez na vida. Quando a dor de dente ocorre em pacientes com enfermidades sistêmicas graves, dos mais diversos tipos, ela deixa de ser um procedimento simples no contexto do doente, embora seja simples no aspecto técnico da abordagem ao dente (Siqueira, 2008). 


\subsubsection{EPIDEMIOLOGIA DA CÁRIE E DA DOENÇA PERIODONTAL}

A causa mais frequente da dor de dente é a doença cárie. Cárie dentária é uma doença infecciosa (bacteriana) que leva à destruição gradativa do dente até torná-lo sensível aos estímulos da cavidade bucal como: escovação, líquidos, alimentos. O governo americano relata, em 2000, que a cárie dentária é a mais simples e comum doença da infância, sendo 5 vezes mais frequente que a asma e 7 vezes mais que as alergias em crianças (Departamento de Saúde Americano, 2000).

Dor de dente, portanto, é mais comum nas populações mais carentes e desfavorecidas e o custo do tratamento nem sempre pode ser bancado pelo indivíduo, no modelo de saúde predominante em nosso país, sendo muito comum a remoção do dente. $\mathrm{O}$ tratamento do dente cariado exige métodos de reabilitação, nem sempre baratos, que não estão disponíveis a todos os pacientes e que ainda são precariamente oferecidos pelo setor público (Departamento de Saúde Americano, 2000).

Nos Estados Unidos da América, em 1993, estudo epidemiológico realizado em 45.711 famílias americanas mostrou que $22 \%$ da população avaliada apresentara dor na boca e na face nos últimos 6 meses (Lipton et al., 1993).

Em 1994 foi realizado inquérito populacional para identificar as queixas das dores mais frequentes na população brasileira (Teixeira, 1994). Esse 
estudo identificou que as lombalgias $(65,9 \%)$ são as mais comuns, seguidas das cefaléias $(60,2 \%)$. Dor de dente (odontalgias) foi queixa de $38,4 \%$ da população abordada.

Estudo, realizado por Goes, em 2001, no Recife, avaliou adolescentes na faixa etária entre 14 e 15 anos que relataram dor de dente nos últimos 6 meses que antecediam a pesquisa. A dor de dente foi considerada leve em $12,1 \%$, desconfortável em $12,8 \%$ e estressante, horrível ou intolerável em $8,7 \%$ das crianças avaliadas. O tempo médio da dor foi de 4,5 dias. Este estudo mostrou que, entre os diversos fatores sócio-demográficos relacionados à dor de dente, como idade e sexo, a condição socioeconômica foi a mais relevante. Os alunos mais carentes economicamente tiveram dor de dente 1,6 vezes a mais que seus colegas de condição socioeconômica mais elevada. Outra curiosidade deste estudo foi de que os últimos nascidos em suas famílias tinham um desempenho escolar fraco e relatavam sentir mais dor de dente no período do estudo. O impacto da dor de dente ocorreu em várias atividades diárias, principalmente na concentração na escola, e atingiu $14,5 \%$ da população estudada, particularmente associada à condição socioeconômica baixa e à maior intensidade da dor de dente.

Outro estudo realizado em escola pública de Florianópolis no ano de 2002, por Nomura et al. em 181 crianças de 12 e 13 anos de idade, reforça a associação entre dor de dente, cárie dentária e nível socioeconômico. Os autores estudaram essa relação e encontraram que mães com até quatro anos 
de estudo tinham 2,5 mais chance de ter dor de dente comparadas às mães com mais de cinco anos de estudo. Crianças de famílias com rendas infereriores a 200 reais tiveram 3,2 mais chance de apresentar dor em relação às de renda superior. Os autores concluiram que alto índice de cárie dentária, baixa escolaridade materna e baixa renda familiar estavam associados à presença de dor de dente da população estudada.

\subsubsection{SAÚde BUCAL EM CRIANÇAS COM DOENÇAS SISTÊMICAS}

Outro aspecto relevante em relação aos dentes e maxilares é verificado em algumas doenças sistêmicas que afetam indiretamente os dentes, como mostrou estudo realizado no Hospital das Clínicas de São Paulo sobre crianças e adolescentes com Artrite Reumatóide Juvenil (Savioli et al., 2004). Essa doença inflamatória é de natureza autoimune, tem manifestação em vários níveis de gravidade e afeta diversas articulações do corpo, como joelhos, ombros e mãos. O estudo mostrou que crianças com maior comprometimento das articulações do corpo têm maior índice de doenças gengivais e de placa bacteriana. Esse fato decorre da dificuldade que apresentam para essa simples tarefa de escovar os dentes.

Crianças com EB, pelo comprometimento da boca desde o nascimento, necessitam de controle odontológico periódico rigoroso, visando a prevenção, chave para a manutenção de uma boa saúde bucal (Krämer, 2010). No entanto, a prevenção em indivíduos com EB pode ser difícil e desafiadora pela alta 
fragilidade da mucosa bucal e alterações bucais que dificultam a higiene bucal e pelo uso restrito de bochechos antissépticos devido a presença do álcool e de agentes aromatizantes (Wright et al.,1993).

Com relação às lesões bucais, Marine e Vecchiet (2001) estudaram a efetividade do sucralfato na mucosa bucal dos pacientes com EBD e observaram que o produto foi capaz de contribuir para melhora do desconforto e reduzir a formação de bolhas.

Além disso, dentes cariados são fontes de infecção e devem ser tratados, pois há risco de septcemia devido à debilidade da gengiva que os cerca, principalmente quando há destruição da coroa dental, e pela progressiva microstomia, que dificulta o acesso aos dentes posteriores (Moscardi et al. 2005). Além disso, os dentes são uma importante fonte de dor aguda nesses pacientes (Fine et al., 2008).

O tratamento odontológico, mesmo nos casos mais leves deve ser realizado com cautela para minimizar os danos aos tecidos bucais (Wright, 2010). Algumas modificações importantes são sugeridas (Harel-Raviv et al., 1995) como a lubrificação dos lábios, da mucosa labial, de luvas e instrumentos, posicionamento do sugador e os dedos sobre tecido duro, drenagem de bolhas hemorrágicas, e manipulação cuidadosa para evitar separação tecidual (Wright et al., 1993; Olsen e Bourke, 1997; Siqueira et al., 2008; Moscardi et al., 2005). 


\subsubsection{O CIRURGIÃO-DENTISTA NA EQUIPE DE CUIDADOS PALIATIVOS}

A boca é frequentemente acometida nos pacientes em cuidados paliativos (Wiseman, 2000). Diversas alterações bucais podem aparecer nesses pacientes, em que a maioria apresenta pelo menos um sintoma ou até mesmo uma associação dos mesmos. Os sinais e sintomas bucais podem ser decorrentes da própria doença, pela terapêutica indicada ou por morbidade associada. Podem aparecer durante todo o curso da doença, porém são mais prevalentes durantes os períodos de tratamento, como nas doenças oncológicas, e particularmente em sua fase terminal (Davies e Finlay, 2005).

As doenças que acometem a boca causam morbidade significativa, além de contribuir para a deterioração do estado geral e psicológico dos pacientes (Davies e Finlay, 2005).

Em geral, os problemas bucais que afetam a população pediátrica como cárie, doenças gengivais, úlceras orais, infecções bacterianas, virais e fúngicas, também estão presentes em crianças e adolescentes em cuidados paliativos (Albandar e Tinoco, 2002; Crespo et al., 2005; Davies e Finlay, 2005; Nunn, 2006). No entanto, podem se manifestar de maneira mais intensa e freqüente pelo comprometimento do estado de saúde geral do paciente, tipo de dieta, medicações, hospitalização prolongada, higiene deficiente e outros (Foster e Fitzgerald, 2005; Nunn, 2006).

Os problemas bucais se não tratados podem resultar em dor, desconforto e comprometimento nutricional, com impacto na evolução e prognóstico da doença (Davies e Finlay, 2005). 
Apesar da filosofia dos cuidados paliativos ser fundamentada em proporcionar conforto total aos pacientes, assim como, a manutenção adequada das funções, normalmente não inclui o cirugião-dentista como membro da equipe (Lapper, 1990; Paunovich et al., 2000), ficando assim a atenção odontológica freqüentemente negligenciada (Wiseman, 2000).

Na maioria dos sistemas de saúde tradicionais, o foco está direcionado ao tratamento da doença, enquanto outras regiões do corpo, como a boca são secundárias, frequentemente é ignorada (Chiodo et al., 1998; Paunovich et al., 2000). Como membro da equipe, o cirurgião-dentista pode: (1) estabelecer o protocolo de tratamento odontológico ou programa de manutenção no momento da admissão do paciente nos cuidados paliativos, já que muitos pacientes apresentam problemas bucais prévios; (2) informar e treinar a equipe e voluntários em relação aos problemas bucais; avaliar continuamente a boca, permitindo diagnóstico precoce; (3) avaliar as necessidades bucais dos pacientes levando em consideração as metas e a filosofia dos cuidados paliativos; e (4) realizar pesquisas para melhoria constante dos cuidados prestados (Lapper, 1990) 


\section{Casuística e Métodos}

\subsection{Casuística}

Os pacientes que constituíram a amostra foram selecionados entre os indivíduos do Ambulatório de Dor e Cuidados Paliativos e do Serviço de Oncohematologia do Instituto da Criança do Hospital das Clínicas da Faculdade de Medicina de São Paulo - ICR-HCFMUSP. Os dados somente foram coletados após assinatura do termo de consentimento livre e esclarecido pelos pais ou responsáveis legais. Este estudo foi aprovado pelo Comitê de Ética em Pesquisa-CAPPesq sob o número 0689/07.

\subsubsection{CRITÉRIOS DE INCLUSÃo}

Pacientes com faixa etária entre 4 a 19 anos que eram acompanhados pela equipe de cuidados paliativos do ambulatório de Dor e Cuidados Paliativos do Instituto da Criança do Hospital das Clínicas da Faculdade de Medicina de São Paulo - ICR-HCFMUS e pacientes da enfermaria do Serviço de Oncohematologia do Instituto da Criança do Hospital das Clínicas da Faculdade de Medicina de São Paulo - SOH/ICR-HCFMUSP acompanhados pela mesma equipe. 


\subsubsection{CRITÉRIOS DE EXCLUSÃo}

Foram excluídos os pacientes com alterações cognitivas e aqueles que não permitiram a realização do exame clínico.

\subsubsection{GRUPOS DE ESTUDO}

Preencheram os critérios para inclusão 42 doentes, em acompanhamento pela equipe de Dor e Cuidados Paliativos, 24 pertencentes ao Ambulatório de Dor e Cuidados Paliativos do ICr/HCFMUSP e 18 à Enfermaria do Serviço de Oncohematologia do ICr/HCFMUSP. Foram excluídos 22 pacientes, 15 pertencentes ao ambulatório e 7 à enfermaria. Os pacientes foram divididos em dois grupos:

-A - Pacientes com epidermólise bolohsa $(n=24)$

-B - Pacientes oncológicos $(n=18)$

\subsection{MÉtodos}

\subsubsection{VARIÁVEIS SÓCIO-DEMOGRÁFICAS}

As avaliações clínicas e odontológicas de todos os pacientes foram realizadas através de anamnese e exame físico. Os dados demográficos referentes ao gênero, idade e etnia deste trabalho foram coletados através de entrevista e anamnese. 


\subsubsection{INSTRUMENTOS DE AVALIAÇÃO}

A avaliação odontológica constou de anamnese e exame físico de acordo com os seguintes instrumentos:

a) Avaliação do prontuário médico (Anexo I): dados pessoais (idade, gênero, procedência, etnia), diagnóstico principal, tempo de doença, tratamentos realizados, medicamentos em uso;

b) Avaliação de dor orofacial: através de ficha clínica da Equipe de Dor Orofacial/ATM do Hospital das Clínicas da Faculdade de Medicina da Universidade de São Paulo (Anexo II), caracterizando entre outros aspectos eventuais dores presentes no seguimento cefálico como: queixa e duração, localização da dor, fator inicial, tratamentos realizados, tipo de dor, freqüência, intensidade, fatores de melhora e de piora, queixa de otalgia e cefaléia freqüentes, presença de bruxismo e palpação da musculatura mastigatória (Siqueira, 2001).

c) Avaliação das condições dos dentes através do índice de dentes cariados, perdidos e obturados (CPO-D) (WHO, 1997) (Anexo III).

d) Avaliação de amplitude de abertura bucal, interincisal e labial por meio de régua flexível milimetrada.

e) Avaliação de qualidade de vida relacionada às atividades de vida diária pelo Childhood Health Assessment Questionnaire (CHAQ) (Anexo IV), instrumento validado na língua portuguesa, preenchido pelos pais ou representante legal, que compreende oito áreas funcionaias de avaliação: (I) vestir-se e arrurmar-se, (II) levantar-se, (III) alimentar-se, (IV) andar, (V) higiene, 
(VI) alcançar, (VII) apanhar, e (VIII) atividades. Em cada uma área pelo menos uma questão é relevante para as crianças de todas as idades. Em cada questão há uma escala de dificuldade com cinco ítens (nenhuma, alguma e muita dificuldade, incapaz de fazer e não aplicável) quantificada em um escore que varia de 0 a 3. A questão com maior escore determina o escore para aquela área funcional. Se instrumentos de apoio são utilizados ou requeridos, o escore mínimo para aquela área funcional é 2 . O índice de incapacidade é medido pela média das oito áreas funcionais. (Machado et al., 2001).

f) Escala de faces e numérica para avaliação da intensidade de dor em crianças menores e maiores de sete anos respectivamente (Anexo V) (McCaffery et al. 1999; Wong et al., 2001).

g) A avaliação da mucosite bucal foi realizada de acordo com os critérios da Escala do National Cancer: grau 0 - nenhum, grau 1 - eritema da mucosa, grau 2 - reação pseudomembranosa focal (zonas e/ou áreas geralmente < que $1,5 \mathrm{~cm}$ de diâmetro e não contíguas), grau 3 - reação pseudomembranosa confluente (zonas e/ou áreas contíguas, geralmente $>$ que $1,5 \mathrm{~cm}$ de diâmetro), e grau 4 - necrose ou ulceração profunda pode incluir sangramento não induzido por trauma menor ou abrasão.

\subsection{ANÁLISE dOS DADOS}

Resultados foram apresentados em mediana (variação) ou média \pm desvio padrão para variáveis contínuas e número (\%) para variáveis 
categóricas. Os resultados foram comparados por meio do test " $\mathrm{t}$ " para as variáveis contínuas para determinar as diferenças entre os grupos A e B. Para as variáveis categóricas, os resultados foram avaliados pelo teste exato de Fisher.

Para os índices CPO-D e questionário de qualidade de vida CHAQ foram utilizados: (1)Teste de Mann-Whitney, com o intuito de verificarmos possíveis diferenças entre ambos os grupos estudados, para as variáveis de interesse; (2)Teste de Friedman, com o intuito de verificarmos possíveis diferenças entre os domínios do bloco de variáveis CPOD e CHAQ, quando comparadas concomitantemente em cada grupo estudado, e (3) Teste dos Postos Sinalizados de Wilcoxon, ajustado pela Correção de Bonferroni, com o intuito de identificar quais variáveis diferem entre si, quando comparadas par a par em cada grupo estudado.

Utilizou-se o programa SPSS (Statistical Package for Social Sciences), em sua versão 17.0, para a obtenção dos resultados. O valor de $p$ menor que 0,05 foi considerado significante. 


\section{Resultados}

\subsection{DADOS DEMOgRÁficos}

Os dois grupos foram homogêneos em relação à faixa etária e distribuição de gênero. A média de idade atual e a freqüência de indivíduos do gênero feminino foram similares entre os grupos $A$ e $B, 10,5 \pm 4,75$ (4 a 18) anos versus $9.6 \pm 3,74$ (5 a 15) anos, $p=0,503 ; 50 \%$ versus $66,6 \%, p=0,350$ respectivamente. O tempo de doença para o grupo $A$ foi maior que no grupo $B$, sem diferença significante, por ser composto por pacientes com EB, doença hereditária que manifesta-se desde o nascimento (tabela 2).

Tabela 2 - Características sócio-demográficas dos grupos A e B

\begin{tabular}{lccc}
\hline Dados sócio-demográficos & $\begin{array}{c}\text { Grupo A } \\
(\mathrm{n}=24)\end{array}$ & $\begin{array}{c}\text { Grupo B } \\
(\mathrm{n}=18)\end{array}$ & $\mathrm{p}$ \\
\hline Idade (anos) & $10,5 \pm 4,75$ & $9.6 \pm 3,74$ & $0,503^{*}$ \\
Gênero feminino & $12(50)$ & $12(66,6)$ & $0,350^{*}$ \\
Tempo de doença (meses) & $132(48-216)$ & $9,5(1-96)$ & $0,137^{* *}$ \\
\hline $\begin{array}{l}\text { NOTA: Valores expressos em mediana (variação) e numérica (\%), com exceção da } \\
\text { idade expressa em média } \pm \text { desvio padrão } \\
\text { Fisher;(**)Teste de Mann-Whitney }\end{array}$ &
\end{tabular}

Dos pacientes do grupo A, 21 (87,5\%) apresentavam diagnóstico de EB distrófica recessiva e $3(12,5 \%)$ de EB distrófica dominante. Dos pacientes do 
grupo B, quatro apresentavam diagnóstico de osteossarcoma, dois de neuroblastoma (IV), seis de tumores do sistema nervoso central, dois de linfoma, e quatro de leucemia. Descrição dos tipos de tumores na tabela 3.

Tabela 3- Tipos de tumores da infância e adolescência encontrados no grupo B

\begin{tabular}{lc}
\hline Tipo do tumor & $\begin{array}{c}\text { Grupo B } \\
(\mathrm{n}=18)\end{array}$ \\
\hline Osteossarcoma & $4(22,2)$ \\
Meduloblastoma & $3(16,6)$ \\
Astrocitoma & $2(11,1)$ \\
Neuroblastoma & $2(11,1)$ \\
Leucemia Linfocítica Aguda & $2(11,1)$ \\
Leucemia Mielóide Aguda & $1(5,5)$ \\
Leucemia Mielóide Crônica & $1(5,5)$ \\
Linfoma de Hodgkin & $1(5,5)$ \\
Linfoma anaplásico & $1(5,5)$ \\
Glioma de tronco & $1(5,5)$ \\
\hline NOTA: Valor expresso em números $(\%)$ &
\end{tabular}

NOTA: Valor expresso em números (\%)

\subsection{QUEIXA BUCAL}

Ambos os grupos apresentaram queixas bucais similares, com exceção de dificuldade de fonação, mobilidade dental, dormência facial e alteração do paladar, presentes apenas no grupo B. Dificuldade de mastigação, disfagia, engasgos, lábios ressecados, e lesões bucais foram mais freqüentes no grupo A que no grupo $B$, com diferença significante, $95,8 \%$ versus $22,3 \%, p<0,0001$; $87,5 \%$ versus $16,6 \%, p<0,0001 ; 41,6 \%$ versus $0 \%, p=0,002 ; 91,6 \%$ versus $33,3 \%, p<0,0001$; e $95,8 \%$ versus $16,6 \%, p<0,0001$ respectivamente. Não 
houve diferença significante em relação às queixas de dor, xerostomia e halitose, $45,8 \%$ versus $38,8 \%, p=0,707 ; 45,8 \%$ versus $27,8 \%, p=0,338$; e $50 \%$ versus $22,2 \%, p=108$ (tabela 4 ).

Tabela 4 - Queixa relacionada à boca nos grupos A e B

\begin{tabular}{lccc}
\hline Queixa bucal & $\begin{array}{c}\text { Grupo A } \\
(\mathrm{n}=24)\end{array}$ & $\begin{array}{c}\text { Grupo B } \\
(\mathrm{n}=18)\end{array}$ & $\mathrm{p}$ \\
\hline Dor & $11(45,8)$ & $7(38,8)$ & 0,707 \\
Xerostomia & $11(45,8)$ & $5(27,8)$ & 0,338 \\
Halitose & $12(50)$ & $4(22,3)$ & 0,108 \\
Dificuldade de mastigação & $23(95,8)$ & $4(22,3)$ & $<0,0001$ \\
Disfagia* & $21(87,5)$ & $3(16,6)$ & $<0,0001$ \\
Engasgos* & $10(41,6)$ & $0(0)$ & 0,002 \\
Lábios ressecados & $22(91,6)$ & $6(33,3)$ & $<0,0001$ \\
Lesões bucais & $23(95,8)$ & $3(16,6)$ & $<0,0001$ \\
Dificuldade fonação & $0(0)$ & $2(11,1)$ & 0,177 \\
Mobilidade dental & $0(0)$ & $1(5,5)$ & 0,428 \\
Dormência facial & $0(0)$ & $1(5,5)$ & 0,428 \\
Alteração do paladar & $0(0)$ & $1(5,5)$ & 0,428 \\
\hline
\end{tabular}

NOTA: Valores expressos em numero (\%); (*) Referente a algum tipo de consistência alimentar: sólida, liquida ou pastosa; Teste exato de Fisher.

Nos pacientes do grupo $\mathrm{A}$, a dor relacionada à boca foi relatada por 11 pacientes (45,8\%). A dor de dente foi relatada em $54,5 \%(n=6)$, na mucosa bucal em 18,1\% ( $n=2)$, na língua em 27,3\% $(n=3)$ e na gengiva em $9 \%(n=1)$ dos pacientes. Foi descrita como latejante em 36,6\% ( $n=4)$, ardor em $54,5 \%$ $(n=6)$ e choque em 18,1\% (n=2). A dor provocada pela mastigação, ingestão de 
líquidos, higiene bucal ou fala foi relatada por $72,7 \%(n=8)$ e espontânea em $27,3 \%(n=3)$. A média do valor da escala numérica de dor foi de 5,1 $\pm 1,4$. A dor no corpo estava presente em $66,6 \%(n=16)$ dos 24 pacientes avaliados, principalmente durante o banho, na troca dos curativos e deslocamentos, como por exemplo do colo da mãe para o chão.

Nos pacientes do grupo B, foi relatada por 7 pacientes $(38,8 \%)$. A dor de dente foi relatada em $11,1 \%(n=2)$, na mucosa bucal em $22,3 \%(n=4)$, na língua em $11,1 \%(n=2)$ e na gengiva em $5.5 \%(n=1)$ dos pacientes. Foi descrita como latejante em $11,1 \%(n=2)$, ardor em $22,3 \%(n=4)$ e pontada em $11,1 \%(n=2)$. A dor provocada pela mastigação, ingestão de líquidos, higiene bucal ou fala foi relatada por todos os pacientes. A média do valor da escala numérica foi de 5,4 $\pm 2,1$. A dor no corpo estava presente em $27,7 \%(n=5)$ dos pacientes avaliados.

\subsection{EXAme Físico Odontológico}

Durante o exame físico intra-bucal, pode-se constatar diversas alterações bucais como microstomia, limitação de abertura bucal, apinhamento dental, anquiloglossia, língua despapilada, lesões de cárie, lesões bolhosas ou fibróticas e perda ou obliteração do fundo de sulco no grupo A (tabela 5). Considerando apenas as lesões bolhosas ou fibróticas observadas em região peribucal e cavidade bucal, constatou-se que as regiões mais acometida foram a língua (83,3\%), seguida pela mucosa labial $(62,5 \%)$ e mucosa jugal $(50 \%)$ (tabela 6). 
No grupo B, foi observada a mucosite oral associada a candidose oral em três pacientes durante o exame físico (tabela 5). Os locais acometidos pela mucosite foram mucosa labial superior e inferior $(n=2)$, soalho bucal $(n=1)$, e mucosa jugal $(n=2)$. Quanto à mucosite observou-se: grau II em dois pacientes e grau III em um paciente.

Com relação a avaliação quantitativa da amplitude de abertura bucal interincisal, observou-se uma maior limitação nos pacientes do grupo A em comparação ao grupo B, com diferença significante, $20,3 \pm 6,1$ versus $36,8 \pm$ $8,3, p<0,0001$ (tabela 7). A abertura labial foi mensurada apenas no grupo $A$ com média de 30,9, e desvio padrão de 6,4.

Tabela 5 - Alterações bucais encontradas ao exame físico intra-bucal nos grupos $A$ e $B$

\begin{tabular}{lcc}
\hline Complicações bucais & $\begin{array}{c}\text { Grupo A } \\
(\mathrm{n}=24)\end{array}$ & $\begin{array}{c}\text { Grupo B } \\
(\mathrm{n}=18)\end{array}$ \\
\hline Microstomia & $23(95,8)$ & $0(0)$ \\
Diminuição ou obliteração do fundo de sulco & $22(91,6)$ & $0(0)$ \\
Anquiloglossia & $23(95,8)$ & $0(0)$ \\
Língua despapilada & $23(95,8)$ & $0(0)$ \\
Lesões bolhosas ou fibróticas (cicatriciais) & $23(95,8)$ & $0(0)$ \\
Mucosite bucal & $0(0)$ & $3(16,6)$ \\
Candidose bucal & $0(0)$ & $3(16,6)$ \\
\hline
\end{tabular}

NOTA: Valores expressos em número (\%). 
Tabela 6 - Localização e prevalência das lesões bucais (bolhas e fibróticas) identificadas no exame físico intra-bucal no grupo A

\begin{tabular}{lc}
\hline Lesão e localização & $\begin{array}{c}\text { Grupo A } \\
(\mathrm{n}=24)\end{array}$ \\
\hline Mucosa labial & $15(62,5)$ \\
Língua & $20(83,3)$ \\
Mucosa jugal & $12(50)$ \\
Palato duro & $8(33,4)$ \\
Palato mole & $1(4,16)$ \\
Lábios & $3(12,5)$ \\
\hline NOTA: Valores expressos em número $(\%)$.
\end{tabular}

Tabela 7 - Avaliação quantitativa da abertura bucal interincisal em milímetros nos grupos A e B

\begin{tabular}{lccc}
\hline & $\begin{array}{c}\text { Grupo A } \\
(\mathrm{n}=24)\end{array}$ & $\begin{array}{c}\text { Grupo B } \\
(\mathrm{n}=18)\end{array}$ & $\mathrm{p}$ \\
\hline Abertura bucal interincisal $(\mathrm{mm})$ & $20,3 \pm 6,1$ & $36,8 \pm 8,3$ & $<0,0001$ \\
& & & \\
\hline NOTA: Teste exato de Fisher & & & \\
\hline
\end{tabular}

\subsection{CONDIÇÃo DENTAL}

As lesões de cárie foram mais frequentemente encontradas no grupo A, ou seja, maior atividade de cárie nos pacientes do grupo A em comparação ao grupo B, com diferença significante, $83,3 \%$ versus $27,7 \%, p=0,0004$. O 
apinhamento dental, decorrente da falta de espaço no arco dentário, foi observado em $91,6 \%$ ( $n=22)$ dos pacientes do grupo A e não foi observado nos pacientes do grupo $B$.

Com relação à avaliação da condição dental mensurada por meio do índice CPO-D, observou-se no grupo A, índice com média de 8,91 e desvio padrão de 5,85. Quando avaliados separadamente e comparados entre si os parâmetros $\mathrm{C}, \mathrm{P}$ e O, apresentaram média de $5,88 \pm 4.94,1,42 \pm 2,30$ e 1,67 $\pm 2,76$ respectivamente, com resultado significante para o parâmetro cariado, $\mathrm{P}$ versus $C, p=0,001$; $O$ versus $C, p=0,005$; e $O$ versus $P, p=0,648$ (tabela 8 e 9). No grupo B, observou-se índice CPO-D com média de 1,7 e desvio padrão de 2,5. Quando avaliados separadamente e comparados entre si, os parâmetros C, $\mathrm{P}$ e $\mathrm{O}$, apresentaram média de $0,44 \pm 0,78,0,44 \pm 1,25$ e $0,89 \pm 1,64$ respectivamente, porém sem diferença significante entre os parâmetros (tabela 10).

\section{Tabela 8 - Comparação entre os parâmetros C, P e O avaliados concomitamente no grupo $\mathrm{A}$}

\begin{tabular}{ccccc}
\hline & $\mathrm{C}$ & $\mathrm{P}$ & $\mathrm{O}$ & $\mathrm{p}$ \\
\hline $\begin{array}{c}\text { Grupo A } \\
(\mathrm{n}=24)\end{array}$ & $\begin{array}{c}5,88 \pm 4.94 \\
(0-17)\end{array}$ & $\begin{array}{c}1,42 \pm 2,30 \\
(0-8)\end{array}$ & $\begin{array}{c}1.67 \pm 2,76 \\
(0-9)\end{array}$ & $\mathrm{p}<0,001$ \\
\hline NOTA: C - cariados, P - perdidos, O - obturados; Teste de Friedman.
\end{tabular}

NOTA: C - cariados, $\mathrm{P}$ - perdidos, O - obturados; Teste de Friedman. 
Tabela 9 - Comparação entre os parâmetros C, P e O par a par no grupo A $(n=24)$

\begin{tabular}{cc}
\hline Par de Variáveis & $p$ \\
\hline P - C & 0,001 \\
O - C & 0,005 \\
O - P & 0,648 \\
\hline
\end{tabular}

NOTA: C - cariados, $\mathrm{P}$ - perdidos, O - obturados; Teste de Teste dos Postos Sinalizados de Wilcoxon, ajustada pela correção de Bonferroni; $(\alpha$ de Bonferroni $=0,016952)$

Tabela 10 - Comparação entre os parâmetros C, P e O avaliados concomitamente no grupo B

\begin{tabular}{ccccc}
\hline & $\mathrm{C}$ & $\mathrm{P}$ & $\mathrm{O}$ & $\mathrm{p}$ \\
\hline $\begin{array}{c}\text { Grupo B } \\
(\mathrm{n}=18)\end{array}$ & $\begin{array}{c}0,44 \pm 0,78 \\
(0-2)\end{array}$ & $\begin{array}{c}0,44 \pm 1,25 \\
(0-5)\end{array}$ & $\begin{array}{c}0.89 \pm 1,64 \\
(0-5)\end{array}$ & 0,756 \\
\hline NOTA: C - cariados, $\mathrm{P}$ - perdidos, O - obturados; Teste de Friedman
\end{tabular}

Quando comparados os parâmetros C, P e O, e CPO-D total entre os grupos estudados, constatou-se que o valor do parâmetro $C$ foi maior no grupo A em comparação ao grupo $B$, com diferenca significante, indicando um maior número de dentes cariados para esse grupo. Com relação ao CPOD total, 
observou-se maior índice para o grupo A em comparação ao grupo B, com diferença significante, o que demonstra uma condição de saúde dental pior, ou seja, uma maior prevalência de cárie para esse grupo (tabela 11).

Tabela 11 - Comparação entre os parâmetros C, O, P e CPOD total entre os grupos A e B

\begin{tabular}{cccc}
\hline CPO-D & $\begin{array}{c}\text { Grupo A } \\
(\mathrm{n}=24)\end{array}$ & $\begin{array}{c}\text { Grupo B } \\
(\mathrm{n}=18)\end{array}$ & $\mathrm{p}$ \\
\hline $\mathrm{C}$ & $\begin{array}{c}5,88 \pm 4,94 \\
(0-17)\end{array}$ & $\begin{array}{c}0,44 \pm 0,78 \\
(0-2)\end{array}$ & $<0,001$ \\
$\mathrm{P}$ & $1,42 \pm 2,30$ & $0,44 \pm 1,25$ & \\
& $(0-8)$ & $(0-5)$ & 0,177 \\
$\mathrm{O}$ & $1,67 \pm 2,76$ & $0,89 \pm 1,64$ & 0,422 \\
& $(0-9)$ & $(0-9)$ & \\
CPO-D TOTAL & $\begin{array}{c}8,96 \pm 5,85 \\
(0-19)\end{array}$ & $\begin{array}{c}1,78 \pm 2,51 \\
(0-10)\end{array}$ & $<0.001$ \\
& & $(0)$ & \\
\hline
\end{tabular}

NOTA: C - cariados, $\mathrm{P}$ - perdidos, O - obturados, CPO-D - cariados, perdidos e obturados; Teste de Mann-Whitney.

Os dois grupos foram homogêneos em relação à não realização de um acompanhamento odontológico regular, $66,6 \%$ versus $44,4 \%, p=0,211$ (tabela 12). Desses pacientes, $20,8 \% \quad(n=5)$ e $38,8 \% \quad(n=7)$ nunca tiveram um acompanhamento odontológico nos grupos A e B respectivamente, e 45,8\% $(n=11)$ do pacientes do grupo A e $5,5 \% \quad(n=1)$ do grupo B tiveram acompanhamento prévio, porém foi descontinuado. Todos os pacientes sem acompanhamento foram encaminhados ao setor de odontologia do Instituto Central (ICHC) e do Serviço de Oncohematologia do HCFMUSP respectivamente. 
A freqüência de higiene bucal de nenhuma vez ao dia (0\% versus $16,6 \%$, $p=0,071)$, uma vez ao dia $(33,4 \%$ versus $44,5 \%, p=0,531)$, duas vezes ao dia $(41,6 \%$ versus $22,3 \%, p=0,321)$, três vezes ao dia $(25 \%$ versus $16,6 \%, p=0,708)$ foram similares entre os grupos A e B (tabela 2). Três pacientes do grupo B não estavam realizando a escovação por dor na boca. Nenhum paciente de ambos os grupos fazia uso de fio dental. Ambos os grupos foram homogêneos em relação ao auxílio do responsável para a higiene bucal, 41,9\% versus 50\%, $p=0,755$.

Tabela 12 - Dados relacionados ao atendimento odontológico regular e higiene bucal nos grupos A e B.

\begin{tabular}{lccc}
\hline Variáveis & $\begin{array}{c}\text { Grupo A } \\
(\mathrm{n}=24)\end{array}$ & $\begin{array}{c}\text { Grupo B } \\
(\mathrm{n}=18)\end{array}$ & $\mathrm{p}$ \\
\hline Atendimento odontológico & & & \\
Sem acompanhamento odontológico & $16(66,6)$ & $8(44,5)$ & 0,211 \\
Higiene bucal & & & \\
Nenhuma vez/dia & $0(0)$ & $3(16,6)$ & 0,071 \\
Uma vez/dia & $8(33,4)$ & $8(44,5)$ & 0,531 \\
Duas vezes/dia & $10(41,6)$ & $4(22,3)$ & 0,321 \\
Três vezes/dia & $6(25)$ & $3(16,6)$ & 0,708 \\
Auxílio do responsável para H.O. & $10(41,6)$ & $9(50)$ & 0,755 \\
\hline
\end{tabular}

NOTA: Valores expressos em número(\%); Teste exato de Fisher 


\subsection{QUALIDADE DE VIDA}

Quanto à qualidade de vida relacionada as atividades de vida diária, pudemos observar um índice de incapacidade com média de 1,8 e desvio padrão de 0,90 , em um escore que varia de 0 a 3 . Os valores de escore entre 0 e 1 foram encontrados em $25 \%(n=6)$, entre 1 e 2 em $25 \%(n=6)$ e maior que 2 em $50 \%(n=12)$ dos pacientes do grupo A. Para o grupo B, observou-se um índice de incapacidade com média de 1,27 e desvio padrão de 1,25 em um escore que varia de 0 a 3 . Os valores de escore entre 0 e 1 foram encontrados em $55,6 \%(n=10)$, entre 1 e 2 em 16,6 \% (n=3) e maior que 2 em $27,8 \%(n=5)$ dos pacientes do grupo $B$.

Quando comparados os parâmetros do CHAQ entre os grupos, observou-se que os domínios III (alimentar-se) e VII (apanhar) apresentaram diferença significante entre os grupos estudados (tabela 13), que demonstra uma maior incapacidade na realização dessas atividades pelos pacientes do grupo A em comparação ao grupo B. Quando comparados os domínios do $\mathrm{CHAQ}$, par a par, foi observado diferença significante apenas para o grupo A, entre os domínios II e VII, e II e VIII, que demonstra maior incapacidade para realizar atividades relacionadas ao domínio levantar-se em comparação às dos domínios apanhar e atividades; e entre os domínios VI e VIII, em que constatase maior incapacidade para realizar tarefas relacionadas ao domínio atividades em comparação às dos domínios alcançar (tabela 14). 
Tabela 13 - Comparação entres os domínios do CHAQ e escore total para a qualidade de vida entre os grupos A e B

\begin{tabular}{cccc}
\hline Variável & $\begin{array}{c}\text { Grupo A } \\
(\mathrm{n}=24)\end{array}$ & $\begin{array}{c}\text { Grupo B } \\
(\mathrm{n}=18)\end{array}$ & $\mathrm{p}$ \\
\hline CHAQ I & $1.88 \pm 1.23$ & $1.44 \pm 1,42$ & 0.238 \\
CHAQ II & $1.29 \pm 1.08$ & $1.28 \pm 1.32$ & 0.874 \\
CHAQ III & $2.0 \pm 1.18$ & $0.83 \pm 1.30$ & 0.005 \\
CHAQ IV & $1.46 \pm 1.29$ & $1.78 \pm 1.40$ & 0.459 \\
CHAQ V & $1.92 \pm 1.10$ & $1.39 \pm 1.50$ & 0.231 \\
CHAQ VI & $1.46 \pm 1.22$ & $1.06 \pm 1.35$ & 0.244 \\
CHAQ VII & $2.33 \pm 1.09$ & $0.89 \pm 1.32$ & 0.001 \\
CHAQ VIII & $2.08 \pm 1.25$ & $1.78 \pm 1.40$ & 0.482 \\
CHAQ escore & $1.80 \pm 0.90$ & $1.27 \pm 1.21$ & 0.160 \\
\hline
\end{tabular}

NOTA: Escore varia de 0 a 3 para todos os domínios; CHAQ (I) vestir-se e arrurmar-se, (II) levantar-se, (III) alimentar-se, (IV) andar, (V) higiene, (VI) alcançar, (VII) apanhar, e (VIII) atividades; Teste de Mann-Whitney. 
Tabela 14 - Comparação entre os domínios do CHAQ, par a par, nos grupos A e B

\begin{tabular}{|c|c|c|}
\hline \multirow[b]{2}{*}{ Par de Variáveis } & \multicolumn{2}{|c|}{$\mathrm{p}$} \\
\hline & $\begin{array}{c}\text { Grupo A } \\
(n=24)\end{array}$ & $\begin{array}{c}\text { Grupo B } \\
(n=18)\end{array}$ \\
\hline CHAQ II - CHAQ I & 0,021 & 0,595 \\
\hline CHAQ III - CHAQ I & 0,618 & 0,059 \\
\hline CHAQ IV - CHAQ I & 0,190 & 0,290 \\
\hline CHAQ V - CHAQ I & 0,850 & $>0,999$ \\
\hline CHAQ VI - CHAQ I & 0,088 & 0,102 \\
\hline CHAQ VII - CHAQ I & 0,027 & 0,041 \\
\hline CHAQ VIII - CHAQ I & 0,494 & 0,290 \\
\hline CHAQ III - CHAQ II & 0,009 & 0,102 \\
\hline CHAQ IV - CHAQ II & 0,438 & 0,038 \\
\hline CHAQ V - CHAQ II & 0,007 & 0,680 \\
\hline CHAQ VI - CHAQ II & 0,360 & 0,194 \\
\hline CHAQ VII - CHAQ II & 0,001 & 0,084 \\
\hline CHAQ VIII - CHAQ II & 0,001 & 0,038 \\
\hline CHAQ IV - CHAQ III & 0,128 & 0,016 \\
\hline CHAQ V - CHAQ III & 0,681 & 0,059 \\
\hline CHAQ VI - CHAQ III & 0,030 & 0,180 \\
\hline CHAQ VII - CHAQ III & 0,057 & 0,655 \\
\hline CHAQ VIII - CHAQ III & 0,837 & 0,016 \\
\hline CHAQ V - CHAQ IV & 0,133 & 0,102 \\
\hline CHAQ VI - CHAQ IV & 0,923 & 0,026 \\
\hline CHAQ VII - CHAQ IV & 0,004 & 0,011 \\
\hline CHAQ VIII - CHAQ IV & 0,014 & $>0,999$ \\
\hline CHAQ VI - CHAQ V & 0,053 & 0,109 \\
\hline CHAQ VII - CHAQ V & 0,013 & 0,038 \\
\hline CHAQ VIII - CHAQ V & 0,495 & 0,102 \\
\hline CHAQ VII - CHAQ VI & 0,001 & 0,083 \\
\hline CHAQ VIII - CHAQ VI & 0,022 & 0,026 \\
\hline CHAQ VIII - CHAQ VII & 0,280 & 0,011 \\
\hline
\end{tabular}

NOTA: CHAQ (I) vestir-se e arrurmar-se, (II) levantar-se, (III) alimentar-se, (IV) andar, (V) higiene, (VI) alcançar, (VII) apanhar, e (VIII) atividades; Teste dos Postos Sinalizados de Wilcoxon,ajustado pela Correção de Bonferron. $(\alpha$ de Bonferroni $=0,016952)$. 


\subsection{CONDIÇÃo GERAL DE SAÚDE}

Dos pacientes avaliados no grupo B, 12 (66,6\%) estavam em quimioterapia e $2(11,1 \%)$ em radioterapia. Em relação ao tratamento prévio, todos os pacientes realizaram quimioterapia em algum momento do tratamento, oito $(44,5 \%)$ foram submetidos a cirurgia para ressecção tumoral, oito $(44,5 \%)$ realizaram radioterapia, e dois $(11,1 \%)$ realizaram TMO, porém com recidiva posterior da doença.

Quando questionados sobre a alimentação, todos os cuidadores relataram que a alimentação apresentava restrições quanto à consistência, temperatura, tempero e textura, para os pacientes do grupo A. Com relação à consistência, referiram que os alimentos precisam ser bem cozidos e amolecidos, cortados em pedaços bem pequenos ou até mesmo batidos. Alimentos ácidos, apimentados ou muito salgados, quentes e de textura áspera nem são oferecidos as crianças para não causar danos à mucosa bucal e gástrica. Nenhum dos pacientes avaliados apresentava via alternativa de alimentação, como sonda naso-enteral e/ou gastrostomia. No grupo B, constatou-se que $16(88,8 \%)$ pacientes alimentavam-se por via oral, um $(5,5 \%)$ paciente apresentava sonda naso-enteral devido à mucosite grave e um $(5,5 \%)$ apresentava gastrostomia por uma disfagia importante. Nenhum paciente apresentava restrições alimentares, seja relacionada à consistência, textura ou tempero, por dificuldade de mastigação e/ou deglutição, apenas orientação 
dietética padronizada pela equipe de nutrição da enfermaria do $\mathrm{SOH} / \mathrm{ICr}$ HCFMUSP.

As complicações da doença mais freqüentes observadas no grupo $A$ foram: prurido $(100 \% / n=24)$, obstipação $(45,8 \% / n=11)$, fadiga $(29,1 \% / n=7)$, alterações do sono $(29,1 \% / n=7)$, dispnéia $(16.6 \% / n=4)$, hipoalbuminemia $(8 ., 33 \% / n=2)$, alterações nas mãos (fusão dos dedos, mãos em luvas) $(50 \% / n=12)$, lesões de pele infectadas, falta de apetite $(16,6 \% / n=4)$, dificuldade de deambulação $(83,3 \% / n=20)$, impossibilidade de deambulação $(16.6 \% / n=4)$, déficit ponduro-estatural $(95,8 \% / n=23)$, distrofia ou ausência de unhas nas mãos $(100 \% / n=24)$, e lesões oculares $(4,16 \% / n=1)$. No grupo $B$ foram: náusea e/ou vômitos $(72,2 \% / n=13)$, falta de apetite $(61,1 \% / n=11)$, fadiga $(50 \% / n=9)$, alopecia $55,5 \% \quad(n=10)$, obstipação $(22,3 \% / n=4)$, alterações do sono $(22,2 \% / n=4)$, dispnéia $(5,5 \% / n=1)$, dificuldade de deambulação $(22,3 \% / n=4)$, e impossibilidade de deambulação $(5,5 \% / n=1)$.

Com relação ao número de medicações usadas pelos pacientes, constatou-se uma média de 3,5 e 6,1 medicações por paciente para os grupo A e $B$ respectivamente. Os analgésicos foram as medicações mais frequentemente usadas pelos pacientes em ambos os grupos ( $75 \%$ grupo A; $77,7 \%$, grupo B). Além desses, no grupo A, destacaram-se os antieméticos $(70,8 \%)$ e antianêmicos (58,3\%) (tabela 15$)$, e no grupo B, os antineoplásicos (77,7\%), antibióticos $(77,7 \%)$ e antieméticos $(55.5 \%)$ (tabela 16$)$. Em relação à escada analgésica da OMS, cerca de 29,1\% ( $n=7)$ faziam uso do I degrau da 
escada e $45,8 \%$ ( $n=11)$ faziam uso do II degrau da escada, nos pacientes do grupo A. Já no grupo B, cerca de $38,8 \%(n=7)$ faziam uso do I degrau da escada, $11,1 \%(n=2)$ e faziam uso do II degrau da escada e $27,8 \%(n=5)$ do III degrau da escada.

Tabela 15 - Medicações em uso pelos pacientes dos grupo A e B

\begin{tabular}{lll}
\hline Medicação & \multicolumn{1}{c}{$\begin{array}{c}\text { Grupo A } \\
(\mathrm{n}=24)\end{array}$} & $\begin{array}{c}\text { Grupo B } \\
(\mathrm{n}=18)\end{array}$ \\
\hline Analgésicos & $18(75)$ & $14(77,7)$ \\
Analgésico não- opioide & $18(75)$ & $14(77,7)$ \\
Adjuvantes & $15(62,5)$ & $7(38,8)$ \\
Analgésico ópioide & $11(45,8)$ & $0(0)$ \\
Antiemético/Antiulceroso/Mobilidade gástrica & $17(70,8)$ & $13(72,2)$ \\
Antihistamínico & $7(29,1)$ & $2(11,1)$ \\
Antianêmico & $14(58,3)$ & $0(0)$ \\
Antibiótico & $1(4,1)$ & $14(77,7)$ \\
Laxativos & $5(20,8)$ & $2(11,1)$ \\
Polivitamínicos & $7(29,1)$ & $2(11,1)$ \\
Antihipertensivo & $1(4,1)$ & $4(22,2)$ \\
Antineoplásicos & $0(0)$ & $13(72,2)$ \\
Anticoagulantes & $0(0)$ & $1(5.5)$ \\
Anticonvulsivante & $0(0)$ & $1(5.5)$ \\
Corticosteróides & $0(0)$ & $6(33,3)$ \\
Antifúngicos & $0(0)$ & $6(33,3)$ \\
\hline
\end{tabular}

NOTA: Valores expressos em número (\%).

Quanto à presença de morbidades associadas, $83,3 \%(n=20)$ e $44,4 \%$ $(n=8)$ dos pacientes do grupo A e B respectivamente, apresentavam mais de 
uma morbidade. As morbidades mais freqüentemente observadas no grupo $A$ foram: anemia ferropriva em 100\% ( $n=24)$, estenose esofágica em $41,6 \%$ ( $n=10)$, refluxo gastro-esofágico em $70,8 \%(n=17)$, doenças cardiovasculares em 12,5\% (n=3), infecções urinárias de repetição em 4,16\% $(n=1)$, osteopenia em 4,16\% (n=1), lesão ocular em 4,16\% (n=1), e depressão em 4,16\% (n=1). No grupo B foram: déficit motor em $22,2 \%(n=4)$, insuficiência renal aguda em 16,6\% ( $n=3)$, hepatoesplenomegalia em 5,5\% ( $n=1)$, anemia hemolítica em 5,5\% $(n=1)$, hipotireoidismo em 5,5\% $(n=1)$ doenças pulmonares em 5,5\% $(n=1)$, crises convulsivas em 5,5\% (n=1), e bexiga neurogênica em 5,5\% (n=1). 


\section{Discussão}

Os dados deste estudo mostram claramente que as crianças que sofrem de epidermólise bolhosa têm grande comprometimento da boca, comparativamente às que apresentam alguma doença oncológica. Para complicar a situação desse grupo de crianças, seu índice de cárie dental é elevada, o que torna a cárie uma morbidade associada que pode contribuir para a piora da sua qualidade de vida, particularmente no que diz respeito às funções realizadas na boca.

Pelo nosso conhecimento esse é um dos poucos estudos que caracteriza essa população de forma mais completa, englobando não só a boca, mas a condição geral de saúde e qualidade de vida, e se considerarmos que a população estudada necessita de cuidados paliativos permanentemente, esse estudo torna-se inédito.

\section{Manifestações bucais da epidermólise bolhosa e da doença} oncológica

É fato que a boca pode ser acometida pela própria doença, debilidade, por uma morbidade associada, e/ou pelo tratamento (Wiseman, 2000, Paunovich et al., 2000; Davies e Finlay, 2006), causando um impacto no prognóstico e evolução da doença.

Em nosso estudo observamos diversas queixas relacionadas à boca em ambos os grupos estudados, que apesar de diferirem quanto à doença e 
tratamento, apresentaram queixas similares, com exceção de dificuldade de fonação, mobilidade dental, dormência em face e alteração do paladar, presentes apenas no grupo $B$, por serem queixas diretamente relacionadas ao tratamento quimioterápico, em que algumas drogas podem causar neuropatia do nervo trigêmeo, que levam à sensação de mobilidade dental, dormência em face e alteração do paladar (Hong e da Fonseca, 2008). A dificuldade de fonação, no entanto, está relacionada aos quadros de mucosites orais, pela dor e desconforto que geram.

Por outro lado, queixas como dificuldade de mastigação, disfagia, engasgos, lábios ressecados, e lesões bucais foram mais freqüentes no grupo A que no grupo $B$, com diferença significante. Isto deve-se ao fato da epidermólise bolhosa, principalmente nos quadros mais graves, levar à um comprometimento do sistema gastrointestinal, inclusive da boca, pela constante formação de bolhas e fibroses cicatriciais, que causam microstomia, anquiloglossia e estenose gastro-esofágica dificultando a mastigação e a deglutição dos alimentos, e consequentemente aos engasgos.

Apesar da língua despapilada ter sido observada na maioria dos pacientes avaliados no grupo $A$, não houveram queixas relacionadas a alteração do paladar, provavelmente pelo fato dessas crianças nunca terem experimentado essa sensação, já que essa alteração se estabelece logo nos primeiros anos de vida, associada à uma restrição alimentar para evitar a formação de bolhas. 
Diversos estudos (Wright et al. 1993; Wright et al. 1994; Wright, 2010) descrevem o acometimento da boca nos pacientes com epidermólise bolhosa, principalmente nos casos mais graves. Devido ao fato de que a amostra do grupo A ter sido composta em sua maioria por um tipo grave de epidermólise bolhosa, a EBDR, também pudemos constatar diversas dessas alterações na maioria dos nossos pacientes (23/95,8\%). O grande envolvimento da boca observado nesse grupo deve-se principalmente a extrema fragilidade da mucosa bucal e peribucal, causadas por mutações no colágeno tipo VII que codifica a ancoragem das fibrilas localizadas abaixo da lamina basal na zona dermo-epidermal da membrana basal (Wright, 2010).

Nos pacientes do grupo B, também foi observado envolvimento da boca, no entanto de maneira menos freqüente e grave, provavelmente pelo fato de que os efeitos dos tratamentos antineoplásicos serem episódicos e temporários, e portanto as alterações bucais decorrentes não estarem presentes no momento da avaliação odontológica.

A limitação da abertura bucal interincisal também foi significativamente maior nos pacientes com epidermólise bolhosa $(p<0,0001)$, em que a média para esse grupo foi de $20,3 \mathrm{~mm}$, valor bem abaixo do considerado normal (acima de $35 \mathrm{~mm}$ ) para a faixa etária avaliada, observado também por SerranoMartinez et al. (2005) e Wright et al. (1991). Já nos pacientes do grupo B, o valor manteve-se dentro da normalidade $(36,8 \pm 8,3 \mathrm{~mm})$. Como esperado, a abertura labial, somente mensurada no grupo A, apresentou média de 30,9 mm, 
confirmando a microstomia, alteração comum nesses pacientes (Fitzpatrick et al., 2001; Watterson et al., 2004 ; Wright, 2010).

\section{A saúde bucal na epidermólise bolhosa e na doença oncológica}

A condição de saúde dental observada no grupo A é alarmante. O índice CPO-D encontrado de 8,96, muito superior ao preconizado pela Organização Mundial de Saúde em 2010, que recomenda um índice CPO-D menor que um para essa faixa etária (Hobdell et al., 2000), ressalta a necessidade de um acompanhamento odontológico precoce e contínuo, se possível, no primeiro ano de vida da criança (Kramer, 2010). Ao mesmo tempo, o parâmetro C (cariados) desse mesmo índice, apresentou diferença significante em relação aos demais parâmetros (perdidos e obturados), demonstrando uma alta atividade de cárie e a necessidade do estabelecimento de um controle de higiene bucal periódico rigoroso.

Quando comparados os parâmetros C, P e O, e CPO-D total entre os grupos estudados, constatou-se que o valor do parâmetro $\mathrm{C}$ foi maior no grupo A em comparação ao grupo B, com diferenca significante, indicando um maior número de dentes cariados no grupo A. Com relação ao CPO-D total, observouse maior índice para o grupo $A$ em comparação ao grupo $B$, também com diferença significante, indicando uma maior prevalência de cárie para esse grupo, e consequentemente uma pior condição de saúde dental.

Diversos fatores podem explicar essa alta prevalência de cárie nos pacientes do grupo A. As freqüentes visitas médicas pela alta morbidade e mortalidade da doença, onde o cuidado bucal fica negligenciado, o medo de 
realizar a higiene bucal, relatado por todos os pacientes e responsáveis avaliados nesse estudo, devido à fragilidade da mucosa, à microstomia e à limitação de abertura de boca que dificultam a higiene, a perda ou obliteração do fundo de sulco e a anquiloglossia que levam ao acúmulo de resíduos na boca, e à falta de orientação precoce contribuem para uma condição de saúde bucal precária nesses pacientes (Wright et al., 1993; Wright et al., 1994; Wright, 2010).

Além disso, 54,6\% dos pacientes desse mesmo grupo queixavam-se de dor de dente em comparação a $11,1 \%$ dos pacientes do grupo $B$, reforçando ainda mais o impacto dessa condição dental precária na vida dos doentes, e sabe-se que a odontalgia interfere na qualidade de vida das crianças e leva à um prejuízo no rendimento escolar (Goes, 2001).

Considerando a gravidade dessas crianças, que pode ser observada também pela quantidade de medicamentos utilizados e pelas complicações das doenças crônicas, ou de suas morbidades associadas, verificar uma condição tão deprimente, como a saúde bucal, a qual poderia ser prevenida, talvez decorra das condições em que é gerida a saúde em um país em desenvolvimento como o Brasil ou das próprias condições socioeconômicas dessa população. Entretanto, considerando o sofrimento das crianças com epidermólise bolhosa é urgente que se criam alternativas para o seu tratamento odontológico, principalmente considerando-se que freqüentam uma instituição de ensino para atendimento terciário à saúde. 
Apesar da existência de um serviço odontológico e de um protocolo de atendimento (Moscardi et al. 2005), direcionado aos pacientes com EB, assim como para os pacientes com câncer, uma parcela considerável desses pacientes $(66,6 \%$ do grupo $A$ e $44,5 \%$ do grupo B) não estavam em acompanhamento odontológico regular, o que justifica o fato que frente à doenças crônicas de alta morbidade e mortalidade, a boca é frequentemente negligenciada devido à preocupação com a saúde geral (Fernandes et al., 2007).

\section{Cuidados paliativos em crianças com doenças crônicas}

O diagnóstico precoce e os constantes avanços na medicina têm aumentado consideravelmente a sobrevida de crianças com doenças crônicas. No entanto, observa-se o impacto da doença e de suas terapias nesses indivíduos, em que a atenção direcionada ao controle e alívio dos sintomas em todas as esferas do cuidado, visando uma qualidade de vida ótima torna-se fundamental.

Apesar da filosofia dos cuidados paliativos ser fundamentada em proporcionar conforto total aos pacientes, assim como, a manutenção adequada das funções, normalmente não inclui o cirurgião-dentista como membro da equipe (Lapper, 1990; Paunovich et al., 2000), ficando assim, a importância do cuidado bucal negligenciada (Wiseman, 2000).

Definir uma criança e/ou adolescente em cuidados paliativos, principalmente nos pacientes oncológicos é desafiador, pois nem sempre é possível determinar quando a doença irá responder as terapias, e também a 
trajetória do processo de morte; aliado ao desconhecimento da atuação e filosofia da equipe paliativista pelos profissionais, e sua constante associação com os cuidados terminais (Harris, 2004; Hutton et al., 2006). Por essa razão, as amostras de ambos os grupos foram pequenas, se pensarmos que entre as inúmeras doenças que limitam a vida, apenas a EB é acompanhada pela equipe de cuidados paliativos pediátricos do ICr/HCFMUSP, e que o baixo número de pacientes com câncer sugere a dificuldade em determinar o insucesso terapêutico, e a consequente progressão da doença.

\section{Qualidade de vida em crianças com epidermólise bolhosa ou com}

\section{doença oncológica}

Em relação à qualidade de vida direcionada as atividades de vida diária, optou-se pela utilização do $\mathrm{CHAQ}$, instrumento utilizado para crianças com artrite reumatóide juvenil (Machado et al., 2001), por não haverem disponíveis até o momento questionários de qualidade de vida direcionados a crianças/adolescentes com EB, e pelo impacto que doença causa na mobilidade dessas crianças pelo envolvimento do sistema musculoesquelético. Apesar de disponíveis na literatura questionários de qualidade de vida para pacientes oncológicos, utilizamos o CHAQ como medida de comparação entre os grupos.

Com relação ao índice de incapacidade geral, medido pelo CHAQ, não houve diferença significante entre os grupos $(p<0,160)$. No entanto, se considerarmos os valores do escore do $\mathrm{CHAQ}$ para cada grupo, observamos que no grupo A metade dos pacientes apresentou escore maior que 2, 
enquanto no grupo $B$ a maioria $(55,6 \%)$ apresentou escore entre 0 e 1 , o que sugere uma maior incapacidade, e consequentemente pior qualidade de vida no grupo A.

Para os domínios III (alimentar-se) e VII (apanhar) do CHAQ, observouse um índice de incapacidade maior nos pacientes do grupo A, quando comparados aos do grupo B, com diferenca significante $(p<0,005$ e $p<0,001)$, provavelmente pelo significante envolvimento dos membros superiores nesses pacientes que dificultam tarefas como cortar alimentos, levar o copo a boca, abrir portas, torneiras e garrafas, algumas das tarefas consideradas nesses domínios.

Quando comparados os domínios do CHAQ, par a par, em ambos os grupos, foi observado diferença significante apenas para o grupo A, e entre os domínios II (levantar-se) e VII (apanhar), II (levantar-se) e VIII (atividades), e VI (alcançar) e VIII (atividades), indicando uma maior incapacidade para realização de tarefas descritas no domínio II em comparação às dos domínios VII e VIII, assim como às do domínio VI em comparação às do domínio VIII.

Existem algumas diferenças marcantes entre os dois grupos avaliados, refletidos pelos resultados obtidos nesse estudo. Por ser uma doença diagnosticada ao nascimento, progressiva e limitante, principalmente nos casos mais graves, e não haver atualmente possibilidade de cura, a EB leva a um maior comprometimento da condição bucal e geral do indivíduo (Fine et al., 2000; Haynes, 2006) observados nesses estudo. 
Já para os pacientes com câncer, a doença acontece em determinado momento da vida, gerando um menor impacto na condição geral de saúde e oral quando comparados aos pacientes com EB, porém não menos importantes. Geralmente, o grau de comprometimento do paciente está relacionados ao tipo e progressão do tumor e das modalidades terapêuticas utilizadas, e mesmo que o paciente em um dado momento não tenha mais a possibilidade de cura, ela existe.

Desta forma, as crianças em cuidados paliativos fazem parte de um grupo extenso de pacientes que apresentam acometimento da boca e necessitam de cuidados bucais e abordagem odontológica regular, levando em consideração a condição de saúde geral do indivíduo, o que demonstra a necessidade de profissionais capacitados para o seu atendimento. 


\section{CONCLUSÕES}

1. As crianças com epidermólise bolhosa em cuidados paliativos têm úlceras e bolhas freqüentes decorrentes da doença e de modo crônico, enquanto as crianças com doença oncológica apresentam episodicamente mucosites associadas ao período de tratamento.

2. As crianças com epidermólise bolhosa apresentaram maior freqüência de dificuldade de mastigação, disfagia, engasgos, dor, xerostomia, halitose, lábios ressecados e lesões bucais, comparativamente com as crianças com doença oncológica. Estas, por sua vez, tiveram mais queixas de dificuldade de fonação, mobilidade dental, dormência facial e alteração do paladar.

3. As crianças com epidermólise bolhosa apresentaram maior gravidade na condição de saúde bucal, especialmente a cárie, comparativamente às crianças com doença oncológica. Quanto as lesões na mucosa bucal, ambos os grupos apresentaram-nas, sendo mais freqüentes nos pacientes com epidermólise. Nestes há seqüelas dessas feridas, o que ocasionou limitação da abertura bucal, interincisal, e pela microstomia, inferiores, comparativamente aos pacientes com doença oncológica.

4. Ambos os grupos apresentaram comprometimento da sua qualidade de vida relacionada às atividades de vida diária. Os pacientes com epidermólise bolhosa apresentaram maior incapacidade nos domínios 
alimentar-se e apanhar do CHAQ, além de maior índice geral de incapacidade para as tarefas diárias, o que configura pior qualidade de vida para esses pacientes. 


\section{ANEXOS}

\section{ANEXO I - AVALIAÇÃO DA HISTÓRIA MÉDICA}

Nome:

DN:

Endereço:

Procedência:

Tel: /

Altura: Peso: Profissão: Sexo: $\square \mathrm{M} \square \mathrm{F}$

Raça: $\square$ L $\square$ M $\square$ Outros:

Diagnóstico médico:

Diagnóstico (s) médico (s) secundário (s):

Internado: $\square \operatorname{Sim} \square$ Não Motivo:

Enfermaria:

Antecedentes individuais:

Tempo de doença:

Hábitos e Vícios:

Medicamentos em uso: 


\section{ANEXo II - FICHA CLÍNICA DA EqUIPDE de DOR OROFACIAL/ATM}

Data:

O paciente está: ( )só ( )acompanhado por ( )cadeira de rodas

\section{ANAMNESE - CARACTERÍSTICAS DA DOR}

1. QP (Qual é a sua queixa?)

2. Há quanto tempo você tem essa dor?: ( )Dias ( )Meses ( )Anos

3. Periodicidade: ( )Diária ( )2-3 X sem ( )Sem ( )Quinz ( )Mensal.

4. Periodo do dia que tem dor: ( )M ( )T ( )N ( )Indiferente

5. Como ela aparece? ( )Espontanea: ( )N ( )S ( )Provocada: ( )N ( )S Como?

6 Quanto tempo dura a sua dor? ( )segs ( )mins ( )horas ( )dias ( )Outro

7. Tipo (caracteristica) da dor: ( )Pontada ( )Peso ( )Queimor ( )Choque ( )Latejante

( )Contínua ( )Outro

8. Intensidade da dor: ( ) fraca ( ) moderada ( ) forte 9. Nota de 0 a 10:

10. Essa dor te acorda durante o sono? ( )N ( )S

11. Período do dia em que a dor é pior: ( )M ( )T ( )N ( )sono ( )indiferente (

)Outro:

13. Sabe o que iniciou a sua dor? ( )N: ( ) S

Como?

14. O que piora a sua dor? --

15. O que acalma a sua dor?

16. Tratamentos realizados para a dor e melhora (M,PM,SM)

17. Possui o hábito de morder: ( ) língua ( ) bochecha ( ) lábios ( ) objetos:

18. Você mastiga do lado: ( )D ( )E ( ) na frente ( ) bil (dos 2 lados)

19. Você acha que sua mastigação é: ( )boa ( )ruim ( )péssima ( )não sabe ( )causa dor Onde?

20. Ao acordar sente alguma dor em seu corpo? ( )N ( )S: ( )rosto ( )ouvido ( )cabeça ( )dentes ( )pescoço ( )corpo ( )Outro

21. Sente o rosto cansado com frequência: ( )N ( )S: ( ) ao acordar ( ) ao mastigar ( ) ao falar ( ) ao sorrir ( ) outro

22. Sabe se range os dentes:( )à noite ( )de dia ( )não sabe ( )N ( )S: Quem disse?

23. Sente ruídos na ( )face ( )cabeça ( )N ( )S: Lado? Quando? ( ) AB ( ) fala

( ) mastiga ( )outro

24. Tem dor provocada por algum movimento da boca? ( )N ( )S - ( ) AB ( ) Protrusão

( ) later. D ( ) Later.E ( )outro

25. Tem dor de ouvido? ( )N ( )S: Lado? ( )D ( )E Passou pelo médico (ORL)? ( )N ( )S:

O que ele disse?

26. Tem dor de cabeça? ( )N ( )S: Onde? 
27. Passou pelo médico (Neuro)? ( )N ( )S - o que ele disse ou receitou?

28. Tem dor no corpo: ( )N ( )S: Onde?

29. Passou pelo médico? ( )N ( )S: Qual? O que ele disse ou receitou?

30. Teve algum acidente, cirurgia ou doença grave? ( )N ( )S - Qual, como e onde afetou seu corpo?

31. Mostre onde é a sua dor. ( )D ( )E ( )Bilateral; e as dores do seu corpo.
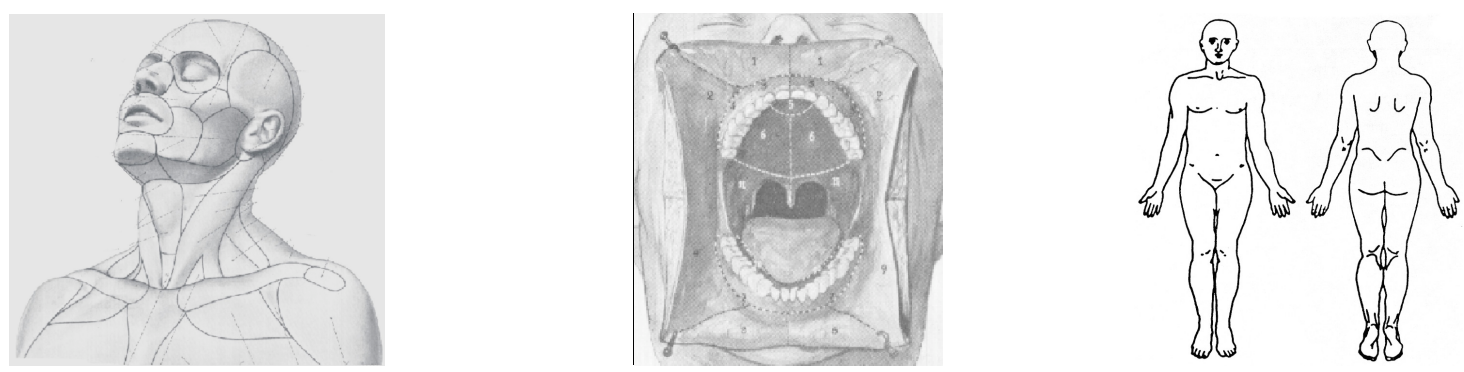

III. ANTECEDENTES MÉDICOS PESSOAIS:

32. Tratou-se de alguma destas doenças:
( )Artrite reumatóide
( )Asma
( )Bronquite
( )Hepatite
( )Amigdalite
( )Derrame (AVC)
( )Fibromialgia ( )Sinusite
( )Pressão alta (HAS)
( )Diabete
( )Úlcera
( )Gastrite
( )Rinite
( )Coração
( )Depressão
( )Doença renal (rins)
( )Parkison
( )Infecções
( )Enxaqueca ( )Herpes zoster (cobreiro)
33. Está em tratamento médico atual? Doenças que tem e remédios que usa:

\section{ASPECTOS PSICOLÓGICOS}

34. Comportamento durante a consulta:

V. EXAME FÍSICO:

35. Face: ( )Assimetria facial ( )Prognatismo ( )Laterognatismo:-D E Hipertrofia: ( )Masseter ( )Temporal - ( )D ( )E

36. Pele da Face:

37. Linfonodos: -

38. Mucosa oral:

39. Lingua:

40. Alterações neurológicas:

41. Periodonto:

42. Dentes:

43. Percussão (Vert e Horiz) (0 a 3 )

\begin{tabular}{llllllllllllllllll} 
& 18 & 17 & 16 & 15 & 14 & 13 & 12 & 11 & 21 & 22 & 23 & 24 & 25 & 26 & 27 & 28 \\
\cline { 2 - 8 } & 48 & 47 & 46 & 45 & 44 & 43 & 42 & 41 & 31 & 32 & 33 & 34 & 35 & 36 & 37 & 38
\end{tabular} 
45. Interferências oclusais:

46. Mordida aberta: ( )S ( )N 46. Mordida cruzada: ( )Ant ( )Post- ( )D ( )E

47. Sobremordida profunda: ( )N ( )S - ( )a ( )b ( )c

48. Desgastes dentários: ( )N ( )S - ( )incisais ( )1/3 incisal ( )1/3 médio ( )1/3 cervical

49. Angle: ( )Cl I ( ) Cl II ( ) Cl III

50. Desdentado Total: ( )Sup ( )Inf ( )Duplo 51. PPR: ( )N ( )S - Qual:

52.Perda de DV:( )N ( )S - _

54. Tempo da PT atual:

; 55.Tempo de uso da PPR:

56. Movimentos mandibulares: AB: $\mathrm{mm}-($ )sem dor ( )com dor - local:

$\mathbf{P}: \ldots+\ldots m m-($ )sem dor ( )com dor - local:

; LD: $\mathrm{mm}-(\mathrm{)}$ sem dor

( ) com dor - local: ; LE: $\mathrm{mm}-($ )sem dor ( )com dor - local:

Linha Media: DLMf: mm ( )E ( )D DLMa: $\mathrm{mm}-() \mathrm{E}() \mathrm{D}$

57. Ruídos na ATM: ( )Ausentes ( )POP ( )crepitação ( ) D ( )E

Estalo D- ( )IA ( )MA ( )FA ( )IF ( )MF ( )FF Estalo E -( )IA ( )MA ( )FA ( )IF ( )MF ( ) FF

58. Palpação da ATM e dos músculos da mastigação e do pescoço:

\begin{tabular}{|l|l|l|l|}
\hline ATM ou & Dir & Esq & Obs. \\
\hline $\begin{array}{l}\text { ATM - pólo } \\
\text { lateral }\end{array}$ & & & \\
\hline $\begin{array}{l}\text { ATM - pólo } \\
\text { posterior }\end{array}$ & & & \\
\hline Masseter Inferior & & & \\
\hline Masseter Médio & & & \\
\hline $\begin{array}{l}\text { Masseter } \\
\text { Superior }\end{array}$ & & & \\
\hline $\begin{array}{l}\text { Masseter Intra- } \\
\text { Oral }\end{array}$ & & & \\
\hline $\begin{array}{l}\text { Temporal } \\
\text { Anteriorr }\end{array}$ & & & \\
\hline Temporal Medio & & & \\
\hline $\begin{array}{l}\text { Temporal } \\
\text { Posterior }\end{array}$ & & & \\
\hline $\begin{array}{l}\text { Temporal Intra- } \\
\text { Oral }\end{array}$ & & & \\
\hline $\begin{array}{l}\text { Digástrico } \\
\text { anterior }\end{array}$ & & & \\
\hline $\begin{array}{l}\text { Digástrico } \\
\text { posterior }\end{array}$ & & & \\
\hline ECM superior & & & \\
\hline ECM medio & & & \\
\hline ECM inferior & & & \\
\hline Esplênio cervical & & & \\
\hline
\end{tabular}




\begin{tabular}{|l|l|l|l|}
\hline $\begin{array}{l}\text { Esplênio da } \\
\text { cabeça }\end{array}$ & & & \\
\hline Suboccipitais & & & \\
\hline Trapézio ombro & & & \\
\hline $\begin{array}{l}\text { Trapézio } \\
\text { pescoço }\end{array}$ & & & \\
\hline
\end{tabular}

59. Movimentos cervicais dolorosos? ( )N ( )S- rotação D ( )rotação E ( )extensão ( flexão

60. Rx, exames ou interconsultas solicitadas:

61. Hipótese Diagnóstica para a dor (CID):

62. Diagnósticos secundários (CID):

63. Diagnóstico final (dor):

64. Tratamento sugerido para a dor:

65. Reabilitações sugeridas:

VI. TRATAMENTO INICIAL (dor): Data:

$1^{\circ}$ retorno - data: ( ) SM ( ) PM ( )S ( )O ( ) SD ( ) M: $\%($ ) $P($ ) I Tratamento realizado: $2^{\circ}$ retorno - data: ( ) SM ( ) PM ( )S ( )O ( ) SD ( ) M: $\% \quad($ ) P ( ) I

Tratamento realizado:

$3^{\circ}$ retorno - data: ( ) SM ( )PM ( )S ( )O ( )SD ( ) M: $\% \quad($ ) P ( ) I

Tratamento realizado:

$4^{\circ}$ retorno - data: ( )SM ( )PM ( )S ( )O ( )SD ( ) M: $\% \quad($ ) P ( ) I

Tratamento realizado:

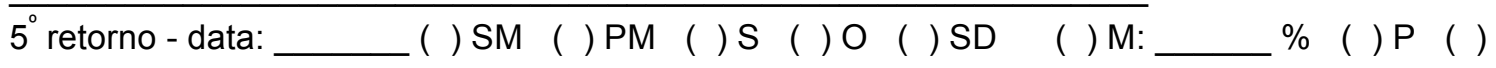
I

Tratamento realizado:

Obs.: 
Anexo III - Avaliação da condição de saúde oral (WHO, 1997)

1. Índice CPO-D: $C P O-D=C+P+O$

$C($ dentes cariados $)=$

$\mathrm{P}($ dentes perdidos $)=$

$\mathrm{O}($ dentes obturados $)=$ 


\title{
Anexo IV - Childhood Health Assessment Questionnaire (CHAQ)
}

\begin{abstract}
Nesta seção estamos interessados em avaliar como a doença do seu filho(a) afeta as suas atividades diárias. Esteja à vontade para escrever quaisquer comentários no verso desta página. Nas questões seguintes, por favor marque a resposta que melhor descreve as atividades habituais do seu filho(a) (em média durante um dia inteiro) DURANTE A SEMANA PASSADA. ASSINALE SÓ AQUELAS DIFICULDADES OU LIMITAÇÕES QUE SÃO DEVIDAS À DOENÇA. Se a maioria das crianças da idade do seu filho não fazem uma certa atividade, por favor marque-a como "Não Aplicável". Por exemplo, se o seu filho tem dificuldade ou é incapaz de desempenhar uma certa atividade porque é muito novo e não porque esteja LIMITADO PELA DOENÇA, por favor marque-a como "Não Aplicável”.
\end{abstract}

\begin{tabular}{|c|c|c|c|c|c|c|}
\hline & & $\begin{array}{c}\text { Sem } \\
\text { NENHUMA } \\
\text { dificuldade } \\
\end{array}$ & $\begin{array}{c}\text { Com } \\
\text { ALGUMA } \\
\text { dificuldade } \\
\end{array}$ & $\begin{array}{c}\text { Com } \\
\text { MUITA } \\
\text { dificuldade } \\
\end{array}$ & $\begin{array}{c}\text { INCAPAZ } \\
\text { de fazer }\end{array}$ & $\begin{array}{l}\text { Não } \\
\text { Aplicável }\end{array}$ \\
\hline \multicolumn{2}{|c|}{$\begin{array}{l}\text { VESTIR-SE E ARRUMAR-SE } \\
\text { (APRONTAR) }\end{array}$} & & & & & \\
\hline \multicolumn{7}{|c|}{ O seu filho é capaz de: } \\
\hline \multicolumn{2}{|c|}{$\begin{array}{l}\text { - Vestir-se, incluindo amarrar os } \\
\text { sapatos e abotoar os botões? }\end{array}$} & & & & & \\
\hline \multicolumn{2}{|c|}{ - Lavar o cabelo? } & & & & & \\
\hline \multicolumn{2}{|l|}{ - Tirar as meias? } & & & & & \\
\hline \multicolumn{2}{|c|}{ - Cortar as unhas das mãos? } & & & & & \\
\hline \multicolumn{2}{|c|}{ LEVANTAR-SE } & & & & & \\
\hline \multicolumn{7}{|c|}{ O seu filho é capaz de: } \\
\hline \multicolumn{2}{|c|}{$\begin{array}{l}\text { - Levantar-se de uma cadeira baixa } \\
\text { ou do chão? }\end{array}$} & & & & & \\
\hline \multicolumn{2}{|c|}{$\begin{array}{l}\text { - Deitar ou levantar-se da cama ou } \\
\text { berço? }\end{array}$} & & & & & \\
\hline \multicolumn{2}{|c|}{ ALIMENTAR-SE } & & & & & \\
\hline \multicolumn{2}{|c|}{ O seu filho é capaz de : } & & & & & \\
\hline \multicolumn{2}{|c|}{ - Cortar a carne ? } & & & & & \\
\hline \multicolumn{2}{|c|}{$\begin{array}{l}\text { - Levar uma xícara ou um copo à } \\
\text { boca? }\end{array}$} & & & & & \\
\hline \multicolumn{7}{|c|}{ - Abrir uma caixa nova de Maizena ? } \\
\hline \multicolumn{7}{|c|}{ ANDAR } \\
\hline \multicolumn{7}{|c|}{ O seu filho é capaz de: } \\
\hline \multicolumn{7}{|c|}{ - Andar na rua, em terreno plano? } \\
\hline \multicolumn{7}{|c|}{ - Subir cinco degraus ? } \\
\hline \multicolumn{7}{|c|}{$\begin{array}{l}\text { * Por favor marque qualquer APOIO ou APARELHOS (Instrumentos) que o seu filho use } \\
\text { habitualmente para alguma das atividades acima indicadas: }\end{array}$} \\
\hline \multicolumn{7}{|c|}{\begin{tabular}{l|l|l|}
\multicolumn{2}{|c|}{ nabitualmente para alguma das atıvidades acıma Indicadas: } \\
- Bengala & $\begin{array}{r}- \text { Instrumentos ou aparelhos usados para se vestir (gancho } \\
\text { de botões, puxador de fechos, calçadeira comprida, etc.) }\end{array}$ & \\
\end{tabular}} \\
\hline - Andador & - Ada & otador de lápis & ou utensílios $\epsilon$ & especiais & & \\
\hline - Muleta & - Cad & eira mais alta & & & & \\
\hline - Cadeira de rodas & - Outr & os (Indique:.... & f................ & f............... & & \\
\hline
\end{tabular}




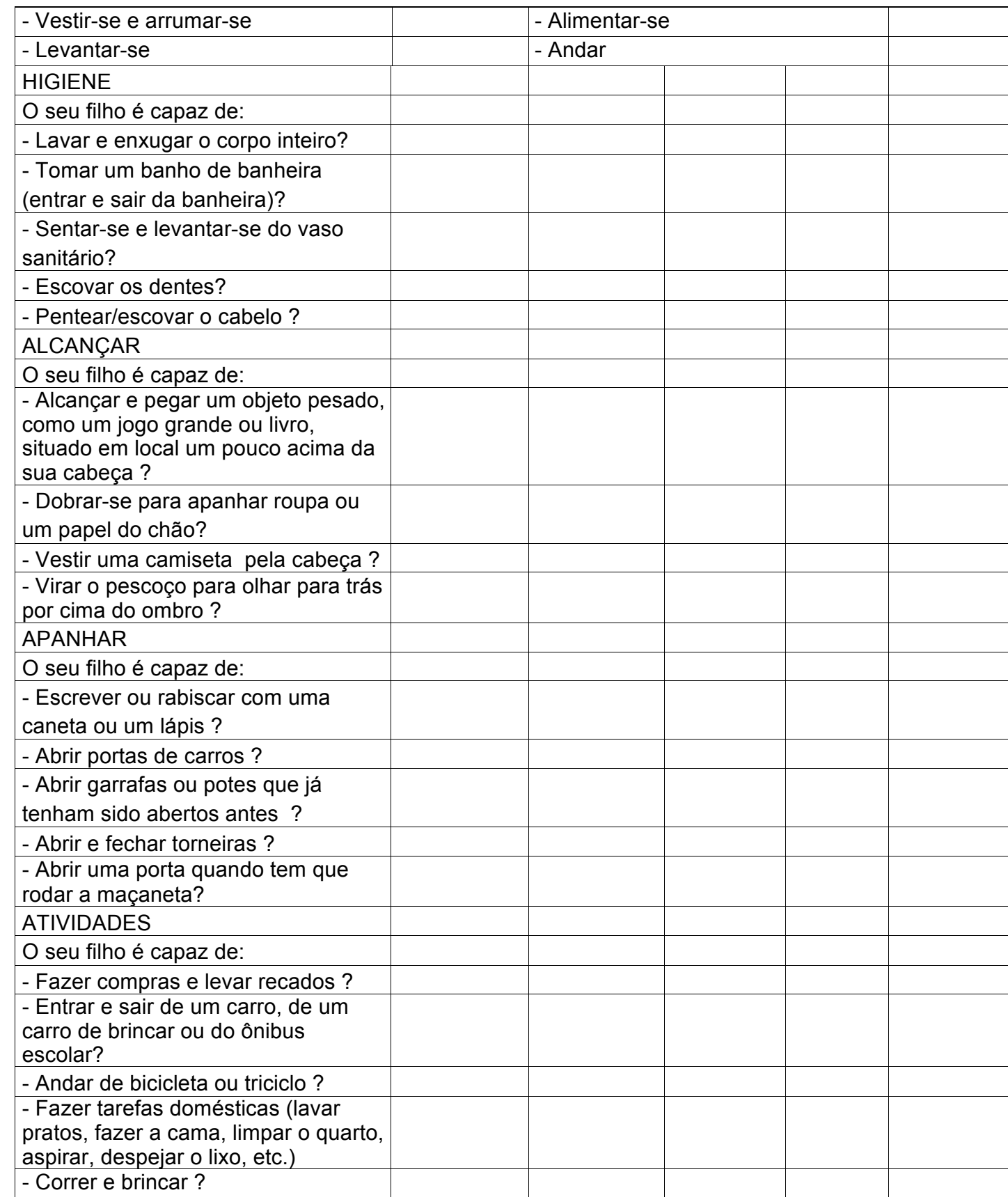

* Por favor marque qualquer APOIO ou INSTRUMENTO que o seu filho use nas atividades acima indicadas:

- Assento de sanitário elevado $\quad$ - Barra de apoio na banheira e sanitário

- Assento de banheira

- Dispositivo para abrir garrafas e

potes (que tenham sido

anteriormente abertos)

* Por favor indique em que tipo de atividades o seu filho habitualmente necessita de ajuda de outra pessoa, DEVIDO À DOENÇA:

- Higiene

- Alcançar

- Apanhar e abrir coisas

- Recados e pequenas tarefas domésticas 
ANEXO V - ESCALA DE FACES E NUMÉRICA PARA AVALIAÇÃo DA INTENSIDADE DE DOR EM CRIANÇAS MENORES E MAIORES DE SETE ANOS RESPECTIVAMENTE (MCCAFFERY ET AL. 1999; Wong ET AL. 2001).

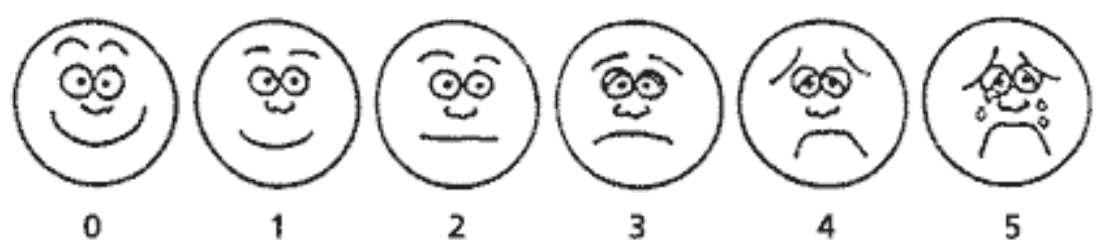

Classificação da dor: 0 - sem dor; 1 a 2 - dor leve; 3 - dor moderada; 4 - dor forte; 5 - dor insuportável

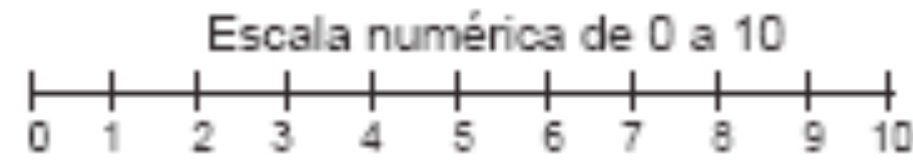

\section{Sem dor}




\section{REFERÊNCIAS}

Album MM, Gaisin A, Lee KWT, et al. Epidermolysisbullosa dystrophica polydysplastica. Oral Surg OralMed Oral Pathol 1977;43:859-872.

American Academy of Pediatrics. Commitee on Bioethics and Commmitee on Hospital Care. Palliative Care for Children. Pediatrics, 2000; 106 (2): 351-357.

Albandar JM, Tinoco EM. Global epidemiology of periodontal diseases in children and young persons. Periodontol 2000. 2002;29:153-176. Review.

Association for Children with Life-Threatening or Terminal Conditions and their Families/ Royal College of Paediatrics and Child Health, 1997. A palliative guide to the development of children's palliative care services. ACT/RCPCH.

Atherton D. Denyer J (2003) Epidermolysis bullosa: an outline for professionals. DeBRa, Bekshire (UK). Disponível em: www.debra.org.uk

Ayers KM, Colquhoun AN.Leukaemia in children. Part I: Orofacial complications and side-effects of treatment.N Z Dent J. 2000 Jun; 96(424):60-65.

Balis FM, Holcenberg JS, Blaney SM. General principles of chemotherapy. In: Pizzo PA, Poplack DG, ed. Philadelphia: Lippincott Williams \& Wilkins; 2002: 237-308.

Barbosa SMM. Cuidados paliativos em pediatria. 2003. Disponível em http//: www.cuidadospaliativos.com.br. 
Braga PE, Latorre MRDO, Curado MP. Câncer na Infância: Analise Comparativa da Incidência, Mortalidade e Sobrevida em Goiânia (Brasil) e outros países. Cad. Saúde Pública, Rio de Janeiro. 2002,8:33-44.

BRASIL, Ministério da Saúde - Coordenação Nacional de Saúde Bucal. Condições de saúde bucal da população brasileira 2002-2003. Resultados Principais. Brasília: Ministério da Saúde, 2004.

Cella D, Pulliam J, Fuchs H, Miller C, Hurd D, Wingard JR, Sonis ST, Martin PJ, Giles F.Evaluation of pain associated with oral mucositis during the acute period after administration of high-dose chemotherapy.Cancer. 2003 Jul 15;98(2):406412.

Chiodo GT, Tolle SW, Madden T. The dentist's role in end-of-life care. Gen Dent. 1998 Nov-Dec;46(6):560-565.

Cohen-Brown G, Ship JA.Diagnosis and treatment of salivary gland disorders.Quintessence Int. 2004 Feb;35(2):108-123. Review.

Crawford E, Burkes EJ, Briggaman R. Herediatry epidermolysis bullosa: oral manifestations and dental therapy. Oral Surg Oral Med Oral Pathol 1976;42: 490-500.

Cheng KK. Oral mucositis: a phenomenological study of pediatric patients' and their parents' perspectives and experiences.Support Care Cancer. 2009 Jul;17(7):829-837. 
Cousin GC.Oral manifestations of leukaemia. Dent Update. 1997 Mar;24(2):6770.

Crespo MRR, Pozo PP del,García RR. Epidemiología de la patología de la mucosa oral más frecuente en niños. Epidemiology of the most common oral mucosal diseases in children. Med Oral Patol Oral Cir Bucal 2005;10:376-387.

Davies A, Finlay I. Oral Care in Advanced Disease. Oxford. 2005.

da Fonseca MA. Dental care of the pediatric cancer patient. Pediatr Dent. 2004 Jan-; 26:53-57.

Department of Health and Human Services. EUA. Oral health in America: A report of the General Surgeon. Executive summary. EUA, 2000.

De Benedittis M, Petruzzi M, Favia G, Serpico R.Oro-dental manifestations in Hallopeau-Siemens-type recessive dystrophic epidermolysis bullosa. Clin Exp Dermatol. 2004 Mar;29(2):128-132.

Epstein JB, Truelove EL, Oien H, Allison C, Le ND, Epstein MS.Oral topical doxepin rinse: analgesic effect in patients with oral mucosal pain due to cancer or cancer therapy.Oral Oncol. 2001 Dec;37(8):632-637.

Fayle SA, Duggal MS, Williams SA.Oral problems and the dentist's role in the management of paediatric oncology patients.Dent Update. 1992 May;19(4):1526, 158-159.

Fayle SA, Curzon ME.Oral complications in pediatric oncology patients.Pediatr Dent. 1991 Sep-Oct;13(5):289-295. 
Fernandes, E. G., Savioli C, Siqueira JTT, Silva AAS. 2007.Oral health and the masticatory system in juvenile systemic lupus erythematosus. In Lupus (Basingstoke). , v.16, 713-719

Fewtrell MS, Allgrove J, Gordon I, Brain C, Atherton D, Harper J, Mellerio JE, Martinez AE. Bone mineralization in children with epidermolysis bullosa. $\mathrm{Br} J$ Dermatol. 2006 May;154(5):959-962.

Feudtner C, Hays RM, Haynes G, Geyer JR, Neff JM, Koepsell TD.Deaths attributed to pediatric complex chronic conditions: national trends and implications for supportive care services. Pediatrics. 2001 Jun; 107(6):E99.

Fine JD, McGrath J, Eady RA.Inherited epidermolysis bullosa comes into the new millenium: a revised classification system based on current knowledge of pathogenetic mechanisms and the clinical, laboratory, and epidemiologic findings of large, well-defined patient cohorts.J Am Acad Dermatol. 2000 Jul;43(1 Pt 1):135-137.

Fine JD. Johnson LB.Weiner M ct al (Genitourinary complications of inherited epiderniolysis bullosa: experience of the national epidermolysis bullosa registry and review of die literature 2004;. J Urol 172(5 Pt 1): 2040-2044.

Fine JD, Johnson LB, Weiner M, Suchindran C. Gastrointestinal complications of inherited epidermolysis bullosa: cumulative experience of the National Epidermolysis Bullosa Registry. J Pediatr Gastroenterol Nutr. 2008a Feb;46(2):147-158. 
Fine JD, Eady RA, Bauer EA, Bauer JW, Bruckner-Tuderman L, Heagerty A, Hintner H, Hovnanian A, Jonkman MF, Leigh I, McGrath JA, Mellerio JE, Murrell DF, Shimizu H, Uitto J, Vahlquist A, Woodley D, Zambruno G.The classification of inherited epidermolysis bullosa (EB): Report of the Third International Consensus Meeting on Diagnosis and Classification of EB. J Am Acad Dermatol. 2008 bJun;58(6):931-50. Epub 2008 Apr 18.

Fine JD, Mellerio JE. Extracutaneous manifestations and complications of inherited epidermolysis bullosa: part I. Epithelial associated tissues. J Am Acad Dermatol. 2009a Sep;61(3):367-384; quiz 385-386. Review.

Fine JD, Mellerio JE.Extracutaneous manifestations and complications of inherited epidermolysis bullosa: part II. Other organs. J Am Acad Dermatol. 2009b Sep;61(3):387-402; quiz 403-404. Review.

Foster H, Fitzgerald J.Dental disease in children with chronic illness. Arch Dis Child. 2005 Jul;90(7):703-708. Review

Freeman EB, Koglmeier J, Martinez AE, et al.Gastrointestinal complications of epidermolysis bullosa in children. Br J Dermatol 2008;158(6):1308-1314.

Fitzpatrick TB, Johnson RA, Wolff K, Suumond D. Dermatologia- Atlas e Texto. $4^{a}$ ed. Rio de Janeiro : Ed. Mc Graw Hill; 2001.

Gannon BA. Epidermolysis bullosa: pathophysiology and nursing care.Neonatal Netw. 2004 Nov-Dec;23(6):25-32. Review. 
Goes PSA. The prevalence, severity and impact of dental pain in Brazilian schoolchildren and their families. (PhD thesis). Department of Epidemiology and Public Heath. University of London; 2001. Thesis.

Goldman A. ABC of palliative care. Special problems of children; BMJ; 316; 4952; Janeiro 1998.

Harris MB.Palliative care in children with cancer: which child and when?J Natl Cancer Inst Monogr. 2004;(32):144-149. Review

Haveman CW. Xerostomia management in the head and neck radiation patient.Tex Dent J. 2004 Jun;121(6):483-497

Haynes L.Nutritional support for children with epidermolysis bullosa. $\mathrm{Br} J$ Nurs. 2006 Nov 9-22;15(20):1097-1101. Review.

Hobdell MH, Myburgh NG, Kellman M, Hausen J. Stteing global goals for oral health for the 2010. Int Dent J 2000; 50: 245-249.

Hong $\mathrm{CH}$, daFonseca $\mathrm{M}$. Considerations in the pediatric population with cancer.Dent Clin North Am. 2008 Jan;52(1):155-181, ix. Review.

Hutchinson F, King N, Hain RD. Terminal care in paediatrics: where we are now. Postgrad Med J. 2003 Oct;79(936):566-568. Review.

Hutton N, Jones B, Hilden JM. From cure to palliation: managing the transition.Child Adolesc Psychiatr Clin N Am. 2006 Jul;15(3):575-84, vii. Review. 
Hyson JL. The child's journey: Transition from health to ill-health. In: Goldman A, Hain R, Liben S. Oxford Textbook of Palliative Care. London: Oxford University Press. (2006). Chap 2, p 14-26.

Instituto Nacional do Câncer- INCA (2009). Disponível em http//: www. inca.gov.br.

Jassal S, Sims J. Working on team. In: Goldman A, Hain R, Liben S. Oxford Textbook of Palliative Care. London: Oxford University Press. (2006). Chap 33, p 513-520.

Jensen SB, Pedersen AM, Reibel J, Nauntofte B.Xerostomia and hypofunction of the salivary glands in cancer therapy. Support Care Cancer. 2003 Apr;11(4):207-225. Epub 2002 Nov 23. Review.

Kirkham J, Robinson C, Strafford SM, Shore RC, Bonass WA, Brookes SJ, Wright JT. The chemical composition of tooth enamel in recessive dystrophic epidermolysis bullosa: significance with respect to dental caries. J Dent Res. 1996 Sep;75(9):1672-1678.

Kirkham J, Robinson C, Strafford SM, Shore RC, Bonass WA, Brookes SJ, Wright JT The chemical composition of tooth enamel in junctional epidermolysis bullosa. Arch Oral Biol. 2000 May;45(5):377-386.

Krämer SM. Oral care and dental management for patients with epidermolysis bullosa.Dermatol Clin. 2010 Apr;28(2):303-309, x. Review.

Krywulak ML.Dental considerations for the pediatric oncology patient. 
J Can Dent Assoc. 1992 Feb;58(2):125, 127-130.

Lapeer GL. The dentist as a member of the palliative care team. J Can Dent Assoc. 1990 Mar;56(3):205-207.

Lipton JA, Ship JA, Larach-Robinson D. Estimated prevalence and distribuition of reported orofacial pain in the United States. J Am Dent Assoc 1993; 124:115121.

Lenton S, Goldman A, Eaton N, Southall D. Development and epidemiology. In: Goldman A, Hain R, Liben S. Oxford Textbook of Palliative Care. London: Oxford University Press. (2006). Chap 1, p 3-13.

Machado CS, Ruperto N, Silva CHM, Ferriani VPL, Roscoe I, Campos LMA et al. The Brazilian version of the Childhood Health Assessment Questionnaire (CHAQ) and the Child Health Questionnaire (CHQ). Clin Exp Rheumatol. 2001;19:S25-9

Marini I, Vecchiet F.Sucralfate: a help during oral management in patients with epidermolysis bullosa. J Periodontol. 2001 May;72(5):691-695.

Margolin JF, Steuber CP, Poplack DG. Acute lymphoblastic leukemia. In: Pizzo PA, Poplack DG, ed. Philadelphia: Lippincott Williams \& Wilkins;2002:489-544.

Ministério da Saúde. Instituto Nacional de Câncer. Coordenação de Programas de Controle do Câncer. "O Problema do Câncer no Brasil", quarta edição revisada e atualizada. Rio de Janeiro, 1997.

Mirra AP, Latorre MRO, Veneziano DB. Incidência, mortalidade e sobrevida do 
câncer da infância no município de São Paulo, 2004. Registro de Cancer de São Paulo. Faculdade de Saúde Pública da Universidade de São Paulo.

Moscardi MF, Soares Junior LAV, Oliveira ZNP, Prado EFGB. Proposta de Protocolo de Tratamento Odontológico em Pacientes com Epidermólise Bolhosa Hereditária. Rev Assoc Paul Cir Dent. 2005; 59(6):425-431.

Nomura LH, Bastos JLD, Peres MA. Dental pain prevalence and association with dental caries and socioeconomic status in school children Southern Brazil, 2002. Braz Oral Res 2004; 18(2):134-140.

Nunn JH. The burden of oral ill health for children. Arch Dis Child. 2006 Mar;91(3):251-253. Review.

Olsen CB, Bourke LF.Recessive dystrophic epidermolysis bullosa. Two case reports with 20-year follow-up. Aust Dent J. 1997 Feb;42(1):1-7.

Pai S, Marinkovich MP. Epidermolysis btillosa: new and emerging trends. 2002; Am J Clin Dermatol 3(6): 371-811.

Paunovich ED, Aubertin MA, Saunders MJ, Prange M. The role of dentistry in palliative care of the head and neck cancer patient. Tex Dent J. 2000 Jun; 117(6):36-45

Pillay E.Epidermolysis bullosa. Part 1: causes, presentation and complications.Br J Nurs. 2008 Mar 13-26;17(5):292-6. Review. Erratum in: Br J Nurs. 2008 Apr 10-23;17(7):413.

Pillay E, Graham-King P (2007). EpidemiolysLs bullosa simplex (adults). 
DebRA, Berkshire (UK). Disponível em: www.debra.org.uk

Savioli C, Silva C, Prado E, Campos L, Ching LH, Siqueira JTT. Dental and Facial Characteristics in Patients with Idiopathic Juvenile Arthritis. Revista do Hospital das Clínicas da Faculdade de Medicina de São Paulo 2004; 59(3):9398.

Scully C, Epstein J, Sonis S.Oral mucositis: a challenging complication of radiotherapy, chemotherapy, and radiochemotherapy. Part 2: diagnosis and management of mucositis. Head Neck. 2004 Jan;26(1):77-84. Review

Sedano HO, Gorlin RJ. Epidermolysis bullosa. Oral Surg Oral Med Oral Pathol 1989;67:555-563.

Serrano-Martínez MC, Bagán JV, Silvestre FJ, Viguer MT. Oral lesions in recessive dystrophic epidermolysis bullosa.Oral Dis. 2003 Sep;9(5):264-268.

Siqueira JTT, Teixeira MJ. Dor orofacial, diagnóstico, terapêutica, e qualidade de vida. Curitiba: Maio; 2001. p. 351-370.

Siqueira JTT. Dores Mudas. As Estranhas Dores da Boca. São Paulo: Artes Médicas, 2008, 270p.

Smith MA, Gloeker Ries LA. Childhood cancer:Incidence, survival and mortality. In: Pizzo PA, Poplack D. Principles and Pactice of Pediatric Oncology. Philadelphia: Lippincott Willians \& Wilkins; 2006. p. 1-12.

Sonis ST.Mucositis: The impact, biology and therapeutic opportunities of oral mucositis. Oral Oncol. 2009 Dec;45(12):1015-1020. Epub 2009 Oct 1 
Sonis ST, Peterson DE, McGuire DB, Williams DA. Prevention of mucositis in cancer patients. J Natl Cancer Inst Monogr. 2001;(29):1-2.

Sonis ST.The pathobiology of mucositis. Nat Rev Cancer. 2004 Apr;4(4):277284. Review.

Sprecher E.Epidermolysis bullosa simplex.Dermatol Clin. 2010 Jan;28(1):23-32. Review.

Sweeney MP, Bagg J. Oral care for hospice patients with advanced cancer. Dent Update.1995; 22:424-427.

Teixeira MJ. 1o. Estudo Master em dor. 10. SIMBIDOR, São Paulo, 1994.

Uitto J, Pulkkincn L. Molecular genetics of hereditable blistering disorders. Arch Dermatol 2001;137(11): 1458-1461.

Uitto J, Eady R, Fine JD, Feder M, Dart J.The DEBRA International Visioning/Consensus Meeting on Epidermolysis Bullosa: summary and recommendations. J Invest Dermatol. 2000 Apr;114(4):734-737. Review.

van Scheppingen C, Lettinga AT, Duipmans JC, Maathuis CG, Jonkman MF. Main problems experienced by children with epidermolysis bullosa: a qualitativestudy with semi-structured interviews. Acta Derm Venereol 2008;88(2):143-150.

Watterson G, Howard R, Goldman A. Peripheral opioids in inflammatory pain. Arch Dis Child 2004;89(7):679-681.

Wiseman MA. Palliative care dentistry. Gerodontology. 2000 Jul;17(1):49-51. 
Whaley LT, Wong DL. Pediatric nursing: Essencial elements for effective interversion. 2nd ed. Rio de Janeiro: Company Guanabara Koogan; 1999:440465.

World Health Organization - WHO: Definition of Palliative Care; 2002. Disponível em: www.who. int./cancer/palliative/definition.

World Health Organization - WHO: Oral health surveys: $4^{\text {th }}$ ed ; 1997. Geneva.

Wright JT, Fine JD, Johnson L. Hereditary epidermolysis bullosa: oral manifestations and dental management.Pediatr Dent. 1993 Jul-Aug;15(4):242248. Review.

Wright JT, Fine JD, Johnson LB.Oral soft tissues in hereditary epidermolysis bullosa. Oral Surg Oral Med Oral Pathol. 1991 Apr;71(4):440-446.

Wright JT, Fine JD..Hereditary epidermolysis bullosa. Semin Dermatol. 1994a Jun;13(2):102-107. Review

Wright JT, Fine JD, Johnson L. Dental caries risk in hereditary epidermolysis bullosa. Pediatr Dent. 1994b Nov-Dec;16(6):427-342.

Wright JT.Oral manifestations in the epidermolysis bullosa spectrum. Dermatol Clin. 2010 Jan;28(1):159-164. Review.

Yates P. Palliative care for specific populations. Aust Fam Physician. 2006 Oct;35(10):776-779. Review. 


\section{APROVAÇÃO}

A Comissão de Ética para Análise de Projetos de Pesquisa - CAPPesq da Diretoria Clínica do Hospital das Clínicas e da Faculdade de Medicina da Universidade de São Paulo, em sessão de 12/09/2007, APROVOU o Protocolo de Pesquisa nº 0689/07, intitulado: "NECESSIDADE DE CUIDADOS PALIATIVOS ODONTOLÓGICOS EM CRIANÇAS COM DOENÇAS CRÔNICAS. CARACTERIZAÇÃO DE AMOSTRA." apresentado pela DIVISÃO DE ODONTOLOGIA, inclusive O Termo de Consentimento Livre e Esclarecido.

Cabe ao pesquisador elaborar e apresentar à CAPPesq, os relatórios parciais e final sobre a pesquisa (Resolução do Conselho Nacional de Saúde $n^{\circ}$ 196, de 10/10/1996, inciso IX.2, letra "C").

Pesquisadores Responsáveis: José Tadeu Tesseroli de Siqueira, Silvia Maria de Macedo Barbosa

Pesquisador (a) Executante: Camila Merida Carrillo

CAPPesq, 14 de Setembro de 2007

Prot. Dr. Ricardo Nitrini

Múćlico Neurologista - HCFMUSP

CRM 17011

Prof. Dr. Eduardo Massad

MATR. 554359 Presidente da Comissão de Ética para Análise de Projetos de Pesquisa

Comissão de Ética para Análise de Projetos de Pesquisa do HCFMUSP e da FMUSP Diretoria Clínica do Hospital das Clinicas da Faculdade de Medicina da Universidade de São Paulo Ruą Ovidio Pires de Campos, 255, 5ª andar - CEP 05403010 - São Paulo - SP Fone: 0113069 
I - DADOS DE IDENTIFICAÇÃO DO SUJEITO DA PESQUISA OU RESPONSÁVEL LEGAL

1.NOME DO PACIENTE .

DOCUMENTO DE IDENTIDADE No : SEXO : .M $\mathrm{F} \square$

DATA NASCIMENTO: ........................

ENDEREÇO

No

APTO:

BAIRRO:

CIDADE

CEP:

TELEFONE: DDD (.

)

2.RESPONSÁVEL LEGAL

NATUREZA (grau de parentesco, tutor, curador etc.)

DOCUMENTO DE IDENTIDADE : SEXO: $M \square \quad F \square$

DATA NASCIMENTO.: .....................

ENDEREÇO:

No

APTO:

BAIRRO:

CIDADE:

CEP:

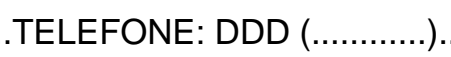

\section{II - DADOS SOBRE A PESQUISA CIENTÍFICA}

1. TÍTULO DO PROTOCOLO DE PESQUISA

Necessidade de cuidados paliativos odontológicos em crianças com doenças crônicas. Caracterização de amostra.

PESQUISADOR: Camila Merida Carrillo

CARGO/FUNÇÃO: Mestranda pelo Departamento de Neurologia da Faculdade de Medicina da Universidade de São Paulo-FMUSP

INSCRIÇÃO CONSELHO REGIONAL DE ODONTOLOGIA No: CROSP 85813

UNIDADE DO HCFMUSP: Divisão de Odontologia/ ICHC

2. AVALIAÇÃO DO RISCO DA PESQUISA:

$\begin{array}{lll}\text { SEM RISCO } \square & \text { RISCO MÍNIMO } 囚 & \text { RISCO MÉDIO } \square \\ \text { RISCO BAIXO } \square & \text { RISCO MAIOR } \square & \end{array}$

(probabilidade de que o indivíduo sofra algum dano como consequência imediata ou tardia do estudo)

3.DURAÇÃO DA PESQUISA : 05 meses 


\section{III - REGISTRO DAS EXPLICAÇÕES DO PESQUISADOR AO PACIENTE OU SEU REPRESENTANTE LEGAL SOBRE A PESQUISA CONSIGNANDO:}

1. Justificativa e os objetivos da pesquisa: Crianças e adolescentes em tratamento de dor ou cuidados paliativos, como é o caso do seu filho (a), podem apresentar problemas na boca, dentes e nos maxilares, em razão da doença ou de seu tratamento. Este estudo tem o objetivo avaliar os problemas mais comuns na boca e na face de pacientes como seu filho (a) para que possamos direcionar os cuidados, proporcionando o alívio de eventuais desconfortos a fim de melhorar a qualidade de vida de pacientes como seu filho (a).

2. Procedimentos que serão utilizados e propósitos, incluindo a identificação dos procedimentos que são experimentais: Serão realizados os exames e tratamentos comuns em Odontologia, como o exame da boca, saliva, dos músculos da face e das articulações da mandíbula. Todos esses procedimentos não são testes novos ou desnecessários, são procedimentos de rotina, bem conhecidos e indispensáveis para conhecer os problemas odontológicos.

3. Desconfortos e riscos esperados: Os riscos dos exames odontológicos são mínimos e são os habituais desses procedimentos, ou seja, um pouco de irritação ou sangramento nas gengivas devido ao exame, um pouco de cansaço no maxilar por permanecer com a boca aberta e um possível desconforto ao realizar a palpação da musculatura da face.

4. Benefícios que poderão ser obtidos: A identificação de problemas na boca ou nos maxilares pode contribuir para o entendimento das manifestações da doença ou de seu tratamento na boca e na face face, prevenindo, quando possível, o seu comprometimento.

5. Procedimentos alternativos que possam ser vantajosos para o indivíduo

\section{IV - ESCLARECIMENTOS DADOS PELO PESQUISADOR SOBRE GARANTIAS DO SUJEITO DA PESQUISA CONSIGNANDO:}

1. acesso, a qualquer tempo, às informações sobre procedimentos, riscos e benefícios relacionados à pesquisa, inclusive para dirimir eventuais dúvidas.

2. liberdade de retirar seu consentimento a qualquer momento e de deixar de participar do estudo, sem que isto traga prejuízo à continuidade da assistência.

3. salvaguarda da confidencialidade, sigilo e privacidade.

4. disponibilidade de assistência no HCFMUSP, por eventuais danos à saúde, decorrentes da pesquisa:.

5. viabilidade de indenização por eventuais danos à saúde decorrentes da pesquisa. 
V-INFORMAÇÕES DE NOMES, ENDEREÇOS E TELEFONES DOS RESPONSÁVEIS PELO ACOMPANHAMENTO DA PESQUISA, PARA CONTATO EM CASO DE INTERCORRÊNCIAS CLÍNICAS E REAÇÕES ADVERSAS.

Camila Merida Carrillo - End.: Av. Dr. Enéas de Carvalho Aguiar, 255 - Cerqueira César - 05403-000 - São Paulo SP - Brasil

e-mail: mila_merida@yahoo.com.br

Tel.: celular: (0XX11) 8388-8558

VI. OBSERVAÇÕES COMPLEMENTARES:

\section{VII - CONSENTIMENTO PÓS-ESCLARECIDO}

Declaro que, após convenientemente esclarecido pelo pesquisador e ter entendido o que me foi explicado, consinto em participar do presente Protocolo de Pesquisa.

São Paulo, de de 2009. 